Article

\title{
Power Quality Improvement Using Distributed Power Flow Controller with BWO-Based FOPID Controller
}

\author{
B. Srikanth Goud ${ }^{1, *(\mathbb{D})}$, Ch. Rami Reddy ${ }^{2}(\mathbb{D})$ Mohit Bajaj $^{3}\left(\mathbb{D}\right.$, Ehab E. Elattar ${ }^{4}$ (D) and Salah Kamel ${ }^{5, *(\mathbb{D})}$ \\ 1 Department of Electrical and Electronics Engineering, Anurag College of Engineering, \\ Ghatkesar 501301, Telangana, India \\ 2 Department of Electrical and Electronics Engineering, Malla Reddy Engineering College (A), \\ Maisammaguda, Secunderabad 500100, Telangana, India; crreddy229@gmail.com \\ 3 Department of Electrical and Electronics Engineering, National Institute of Technology Delhi, \\ New Delhi 110040, India; mohitbajaj@nitdelhi.ac.in \\ 4 Department of Electrical Engineering, College of Engineering, Taif University, P.O. Box 11099, \\ Taif 21944, Saudi Arabia; e.elattar@tu.edu.sa \\ 5 Department of Electrical Engineering, Faculty of Engineering, Aswan University, Aswan 81542, Egypt \\ * Correspondence: srikanth.b@anuraghyd.ac.in (B.S.G.); skamel@aswu.edu.eg (S.K.)
}

check for updates

Citation: Goud, B.S.; Reddy, C.R.; Bajaj, M.; Elattar, E.E.; Kamel, S. Power Quality Improvement Using Distributed Power Flow Controller with BWO-Based FOPID Controller. Sustainability 2021, 13, 11194. https: / / doi.org/10.3390/su132011194

Academic Editor: Dimitrios Thomas

Received: 25 August 2021

Accepted: 5 October 2021

Published: 11 October 2021

Publisher's Note: MDPI stays neutral with regard to jurisdictional claims in published maps and institutional affiliations.

Copyright: (c) 2021 by the authors. Licensee MDPI, Basel, Switzerland. This article is an open access article distributed under the terms and conditions of the Creative Commons Attribution (CC BY) license (https:// creativecommons.org/licenses/by/ $4.0 /)$.

\begin{abstract}
The integration of hybrid renewable energy sources (HRESs) into the grid is currently being encouraged to meet the increasing demand for electric power and reduce fossil fuels which are causing environmental-related problems. Integration of HRESs into the grid can create some power quality (PQ) problems. To mitigate PQ problems and improve the performance of grid-connected HRESs some flexible devices should be used. This paper presents a distributed power flow controller (DPFC), as a type of flexible device to mitigate some PQ problems, including voltage sag, swell, disruptions, and eliminating the harmonics in a hybrid power system (HPS). The HPS presented in this work comprises a photo voltaic (PV) system, wind turbine (WT) and battery energy storage system (BESS). As a result, black widow optimization (BWO) with DPFC with real and reactive power (DPFC-PQ) is built in this paper to solve the PQ issues in HRES systems. The main aim of the work is to mitigate PQ problems and compensate for load demand in the HRES scheme. The controller used to drive this DPFC-PQ is a fractional-order PID (FOPID) controller optimized by the black widow optimization (BWO) technique. To assess the capability of BWO in fine-tuning the FOPID controller parameters, twelve optimization techniques were presented: P\&O, PSO, Cuckoo, GA, GSA, BBO, Whale, ESA, RFA, ASO, and EVORFA. Additionally, a comparison between the FOPID controller and the classical PI controller is introduced. The results showed that the proposed BWO-FOPID controller for DFPC had mitigated the PQ problems in grid-connected HRESs. The system's performance with the presented BWO-FOPID controller is compared with eleven optimization techniques used to optimize the FOPID controller and also compared with the conventional PI controller. The design of the proposed system is implemented in the MATLAB/Simulink platform and performances were analyzed.
\end{abstract}

Keywords: DPFC; HRES; voltage sag; voltage disturbances; voltage interruptions; voltage swell; harmonics

\section{Introduction}

HRESs are currently playing a vital role, as traditional energy sources face several challenges related to the usage of fossil fuels that have great negative environmental impacts. HRESs can mitigate emissions and global warming in addition to their significant economic advantages [1]. Due to global economic problems and increasing ecological awareness, HRESs-based distributed generation (DG) is becoming more relevant [2]. Many HRESs have been implemented and integrated into the classical power networks, like wind energy, photovoltaic energy, fuel cells (FCs), and biomass [3]. Each RES has distinct characteristics different from other sources in terms of being AC or DC [4]. The PV and FC generated DC voltages with different levels, while wind energy generates either AC or DC based on the 
generator used in the wind energy conversion system (WECS) [5]. These diversities represent a challenge in connecting these HRESs to the electrical network. Another challenge that appears when integrating these HRESs into the electrical grid is the instability of the power generated from HRESs due to their dependence on some changing environmental conditions, such as temperature and irradiance in PV systems and wind speed in WECSs. The critical solution to such challenges is using power electronic devices to adjust the DC levels of all DC sources using some converters. Besides, these converters may be used for maximizing the power extracted from each HRES [6]. Then DC-AC inverters are used to connect the output of these HRESs to the electrical grid. The power electronic devices, used to integrate different types of HRESs to the grid, will increase the PQ problems, such as voltage sags, swell, disruptions, interference harmonics, etc. These problems might cause continuous fluctuation in power generated and tripping of some HRESs if the grid standards or codes were not fulfilled [7]. Some flexible devices should be added to the whole system to support the PQ and improve system performance; these devices are called flexible AC transmission system (FACTS) devices [8]. According to these FACTS devices' connection to the network, there are three types: series, parallel, and combination of series and parallel. These controllers are identified based on their specific characteristics and controlling mechanism before integrated into the system. To change the line reactance and expand the limit of transmission line, a static synchronous series compensator (SSSC) and the dynamic voltage restorer (DVR) are used [9]. Shunt types are utilized for supporting the voltage by exchanging the reactive power with the system during voltage sag/swell conditions. Shunt compensators like static compensators (STATCOM), distribution STATACOM (DSTATCOM), and thyristor regulated reactor (TCR) were introduced to improve the connection of some RESs to the grid [10]. The series/shunt combination of these FACTS devices combined the characteristics of the series and the shunt devices like the unified power flow controller (UPFC) and distributed power flow controller (DPFC) [11,12]. UPFC is a combination of STATCOM and SSSC linked together through DC link to exchange the active/reactive with the system. Some modifications in the structure of UPFC is performed by eliminating the DC link capacitor and connecting STACOM and SSSC through a transmission line with third-frequency components [13]. This elimination of the DC link gives more prominent adaptability to put the STATCOM and SSSC autonomously. Based on the discussions above, some FACTS devices are needed to support the PQ issues in grid-connected HRESs. The performance of the type of FACTS devices mainly depends on the controller used. The traditional PI controller and the modified fractional-order proportional integral controller (FOPIC) are the most dominant due to their simplicity and good performance with the superiority of the FOPI type [14]. Adjustment or tuning the controller parameters of FOPID employed in FACTS devices to mitigate the PQ problems in grid-connected HRESs is a non-linear complex optimization problem that desires some metaheuristic optimization techniques. Many optimization techniques were presented for optimal tuning of PI and FOPID controller parameters in many HRES applications [15].

This paper presents the utilization of one of the combined FACTS devices, DPFC, to mitigate some PQ problems in a grid-connected HRES system. This system consists of wind, PV, and batteries as storage units. The PQ issues presented in this paper are the irregularity in power generated, voltage sag, swell, disruption conditions, and the total harmonic distortion (THD). The power irregularity comes from PV and wind energy conversion systems due to variation in the irradiance and wind speed, respectively. At the same time, non-linear loads simulate the harmonics in the system. In the proposed system, the instantaneous PQ theory and FOPID controller with BWO are initialized. To provide the optimal pulses to the converter the instantaneous PQ theory is used for the series and shunt controllers. The results of the proposed system are validated by comparing them with the results of the conventional PI controller and the intelligent techniques like P\&O, PSO, Cuckoo, GA, GSA, BBO, Whale, ESA, RFA, ASO, and EVORFA. Among all the controllers BWO provides the best control parameters to the FOPID controller which produces better performances in terms of compensation of voltage and current related swell, sag, and harmonic reduction. The proposed framework is developed and examined in MATLAB/Simulink. The rest of the paper is composed as follows; 
Section 2 describes a brief survey of recent research works, Section 3 proposes the HRES system, Section 4 proposes control model of DPFC, Section 5 a BW optimization, in Section 6 we present results and discussions, Section 7 includes a comparison analysis, and Section 8 is the conclusion.

\section{A Brief Review: Recent Research Works}

Researchers at several research institutions use various ways to minimize the PQ issues associated with integrated FACT devices. In this paper, we look at some of the work that has been done on PQ issue mitigation and it is presented in Table 1.

Table 1. Survey of previously published work.

- $\quad$ They have presented that the bacterial graphical user interface oriented by particle swarm optimization method for optimization of various type DFACTS for power quality improvement in the distribution system.

- $\quad$ EBFO based multiple DFACTS allocation utilizing DSSSC, APC, and DSTATCOM are preferred to decrease power losses, improve load balancing, and increase voltage deviation index to $70 \%, 38 \%$, and $132 \%$, correspondingly, and also it may improve loading factor without extra power loss.

- The multi-objective issue in which four objective functions include the maximization of voltage stability, power loss reduction, and minimizing of voltage deviation and equalizing the feeder load balancing in the distribution system.

- $\quad$ The single-phase voltage source inverter that connects the distributed generation plant to the grid must address several issues related to the quality of current injected into the grid, output power factor, and power exchange between the plant and the grid.

- $\quad$ For single-phase grid linked VSI, the model predictive current controller (MPCC) is developed, which can perform well in both steady-state and transient state operations.

- $\quad$ The current study also shows how to build the digital MPCC in hardware utilizing a low-cost digital signal processor (DSP). A single-phase grid-connected VSI of $1 \mathrm{~kW}$ is modeled and simulated.

- $\quad$ They proposed the DSTATCOM method for minimizing power quality problems during power delivery. One of the unique power gadgets was this technique.

- Some of the features such as reimbursement of imaginary power, reduction of voltage harmonics, reduction of power factor, and reduction of current harmonics were accomplished using the DSTATCOM method.

- In terms of utilizing these methods, the primary goal was to improve power quality by minimizing noise and reducing voltage fluctuation. Authentication and demonstration of the suggested method were carried out here.

- $\quad$ They proposed the unified power quality conditioner (UPQC) method for improving power quality. The achievement of UPQC's series and shunt active power filter (APF) virtual power-sharing.

- These methods of power-sharing were predicated on the instability of the voltage source. Some of the problems arose as a result of voltage level instabilities.

- $\quad$ To overcome these problems, a combination of power angle control (PAC) and synchronous reference frame (SRF) was employed. Parameters like load current were utilized to mitigate power quality problems while efficiently using the UPQC inverters.

- $\quad$ They proposed that the two methods, UPQC-O and PV array with battery and UPQC-O and PV array without batteries, be combined. In the method of UPQC-O and PV array with battery, the PV array generates some quantity of energy that is often stored. Those energies were used during peak hours to conduct efficient energy storage operations.

- $\quad$ The PV array was injected directly into the network in the UPQC-O and PV array without the battery method. These two methods were coupled with operational parameters like bus voltage.

- In this case, the replacement was done in terms of UPQC-O with the PV array in the networking methods. Some of the goals include lowering the operating costs of batteries, PV arrays, and inverters, as well as reducing energy loss. In addition, the particle swarm optimization method was utilized to improve the energy preservation solution. 
Table 1. Cont.

\section{Contribution}

Year Reference

- $\quad$ They proposed a static synchronous compensator (STATCOM). This method was used to reduce reactive power using the Icos algorithm. In this method, the continuous power supply was maintained while conducting the power quality enhancement.

- $\quad$ The uninterrupted power supply protects both the telecommunications and computer systems.

Some supply-side commotion, such as sag, swell, and harmonics, were reduced as compensation for poor power quality. Voltage and current were both unstable; therefore they were balanced.

- $\quad$ They demonstrated the multi-functional grid-connected inverter (MFGCI) for increasing power quality in both micro-grid (MG) and distributed generation (DG) systems.

- $\quad$ The MFGCI method was used to reduce the voltage-based power quality approach reimbursing. In addition, the shunt series switched multi-functional grid-connected inverter (SSS-MFGCI) method was utilized to address both current and voltage-based power quality problems.

- $\quad$ They proposed using the shunt active power filter (SAPF) method to minimize power supply problems. This kind of technique was also used to reduce harmonic turbulences.

- This filter was specifically designed for regulating DC voltage amid power quality. In this method, the total harmonic distortion (THD) value was evaluated in terms of harmonic mitigation. In this technique, sinusoidal waveforms were generated to mitigate power quality problems.

- They had developed a control method that could give a fast and reliable solution as the operating conditions of the system varied. The UPQC coupled wind energy to increase energy quality is the design of the technique.

- Voltage sag, source tension swell, and current source power harmonics reduction. The Adaptable PI controller has been used in shunt-based and serial APFs, which enable the adaptive PI controller using the Park control mechanism. This signifies that there are no anomalous effects on any modification to the external state of the system depicted.

- $\quad$ They proposed a shunt active power filter and a series active power filter for improving power quality. The adaptive ANFIS method was utilized to assess power quality performance in UPQC devices.

- $\quad$ Some drawbacks, including voltage swell and voltage sag, exist with UPQC devices. These types of problems were minimized by using UPQC-based methods.

- $\quad$ They had introduced a hybrid flow management approach (PFM) of the micro-grid (MG) connected hybrid renewable source (HRES). This strategy is proposed by the integration of both the whale optimization algorithm (WOA) and the SSAWO squirrel search (SSA) algorithm.

- Here the SSA develops voltage source inverter control signals subject to the power exchange difference between the source and the load side. The multi-objective function is determined by the active and reactive power variants needed for the grid generated using the accessible source power.

The technology-based control model created improve the power controller control parameters, given the variety of power flows.

- $\quad$ They proposed an enhanced fuzzy-based multi converter-unified power quality conditioner for improving power quality (MC-UPQC). Using this method also helped to reduce inefficiencies in voltage and current.

- In addition, the fuzzy incremental conductance method was utilized to determine the power point that occurs at the maximum level. Using this fuzzy-based method, the wind energy system (WES) was enhanced.

- $\quad$ They proposed a new technique for DVR. They optimized FOPID controller with GS algorithm.

- They have addressed various PQ issues like voltage regulation, fault compensation, sag, swell, and THD reduction.

\section{Modeling of the Proposed HRES System}

In the distribution system, HRESs such as PV and WT are used more extensively. HRES is considered to be the best option in an integrated DG system [29]. In the distribution system, HRES should satisfy the load demand expected by customers, which implies problems of flexibility and reliability of power quality [30]. For the smooth running of the device, these PQ issues must be avoided [31]. FACT devices are utilized with the 
development of power electronics devices to mitigate PQ problems. DPFC is designed to mitigate power PQ problems such as voltage sag, current sag, disruptions, and THD [32]. The combination of PV, WT, and the battery as energy storing system (BESS) interfaced with the grid is proposed. As the sources considered are intermittent, BESS is designed to satisfy the load demand under critical environmental conditions. PQ problems are generated in the HRES system because of the faults, non-linear loads, and sudden loads. [33]. Due to these problems, voltage instability and mismatches in reactive power are created. PQ issues such as voltage sag, current sag, real power, reactive power, and THDs are discussed in this paper [34]. To improve the voltage regulations in the HRES interfaced grid-connected system DPFC-FOPID controller is designed to solve these problems. The tuning of the FOPID controller which controls the operation of the series controller and shunt controller is done using the $\mathrm{BWO}$ technique. Using perturb and observe $(\mathrm{P \& O})$ maximum power point tracking (MPPT), the PV and wind powers are derived [35]. A reference DC bus voltage is produced from the BWO. The DC relation voltage reference is set to its default value at a time when there is no solar energy [36]. The HRES's PQ problems are considered primarily due to faults, non-linear load, and sudden grid side loads [37].

The proposed system is equipped with DPFC, shown in Figure 1 [38]. It comprises series and shunt controllers which are operated using control techniques to compensate the PQ problems and for stable operation power compensation can be accomplished by providing the best gain parameters for the FOPID controller [39], which filters and injects the necessary power by selecting the best gain parameters for the FOPID controller. The FOPID controller is controlled by a BWO technique, which is programmed to select the values necessary to run the control operation under PQ conditions [40].

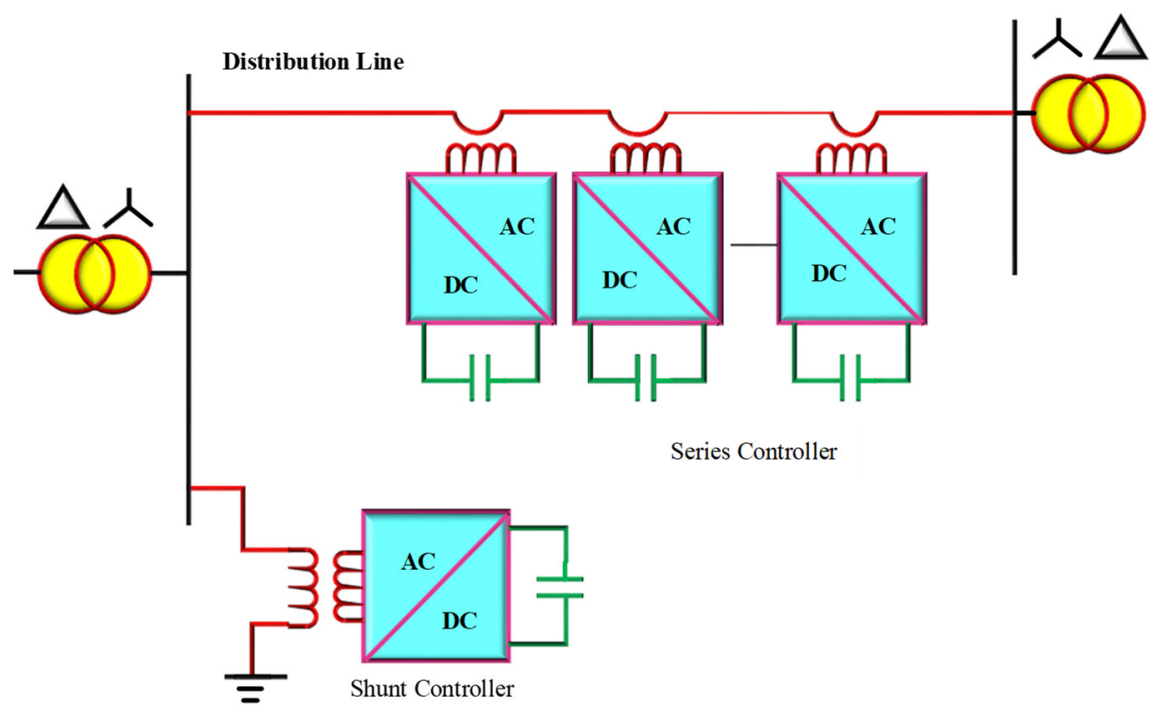

Figure 1. The architecture of DPFC.

\subsection{Modeling of $P V$}

The design PV panel current and terminal voltage are computed based on the following Equations (1)-(3) [41].

$$
\begin{gathered}
I_{P}=I_{S C}-I_{0}\left\{\exp \left[\frac{Q}{a k t}\left(V_{P}+I_{P} R_{S E}\right)-1\right]\right\}-\frac{V_{P}+I_{S C} R_{S E}}{R_{S H}} \\
V_{P}=\frac{a k t}{Q} \ln \left\{\frac{I_{S C}}{I_{P}}+1\right\}
\end{gathered}
$$

The PV is the ideal option for producing power from solar energy from various HRESs while avoiding greenhouse gas pollution, with durability, long life, good efficiency, and less maintenance. It consists of cells connected in series in the PV system to achieve the voltage 
required. Figure 2 shows the built PV panel model, the power produced from the PV panel is formulated as follows.

$$
P_{P V}(t)=N_{p v}(t) \times I_{p v}(t) \times V_{p v}(t)
$$

The maximum power extraction from the grid would not always exist as the variations in both the load and the environmental conditions and, consequently, the current drawn from HRESs, especially PV systems.

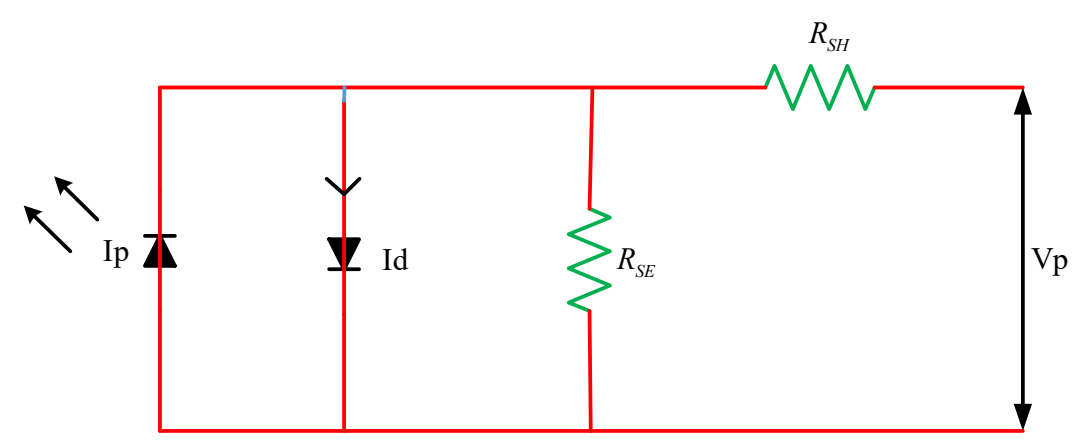

Figure 2. Model of PV [41].

\subsection{Modeling of Wind Turbine}

The output power produced by the WT is dependent on the wind speed under the stated hub height. WT power is expressed as (4). The PV and WT systems on the grid side are used to compensate for load requirements. Often the requirement for load rises, which cannot be covered by HRES, because the battery is often attached to the device. The battery system's statistical modeling is presented in the section below.

$$
P_{W} T(t)=\left\{\begin{array}{c}
0, V<V_{\text {cutin }} \text { or } V>V_{\text {cutout }} \\
P_{W T}^{M A X}\left(\frac{P_{W T}^{c O}-P_{W T}^{M A X}}{V_{\text {cutout }}-V_{r}}\right)\left(V(t)-V_{r}\right), V_{r}<V \leq V_{\text {cutout }} \\
P_{W T}^{M A X}\left(\frac{V(t)-V_{\text {cutin }}}{V_{r}-V_{\text {cutin }}}\right)^{3}, V_{\text {cutin }} \leq V \leq V_{r}
\end{array}\right.
$$

\subsection{Modeling of BESS}

When the power provided by the HRES is insufficient, the battery meets the needed load requirement. The battery output is calculated using the reference autonomy day (AD) under the condition of the system's required power consumption. AD is defined as the total number of days that the battery is capable of producing power to counterbalance the demand for loads. This battery output may be described as (5).

$$
B^{\text {capacity }}=\frac{\text { Autonomyday } \times P^{L}}{\eta^{I} \times \eta^{B} \times D O D}
$$

The battery in the HRES system is charged using the excess electricity produced by RES. The battery capacity is calculated using Equations (6) and (7). State of charge (SOC) is a critical parameter in the battery related to further energy production and energy shortfall in HRES as discussed below. It can impact PQ issues such as sag, swell, voltage interference, and so on in the proposed design framework. The problems of power efficiency in the system must be resolved to increase the reliability of the system obtained with the usage of the DPFC unit in the HRES system. In the segment below, the modeling of DPFC is discussed.

$$
B^{P}=P_{P V}(t)+P_{W T}(t)-\frac{P_{L}(t)}{\eta^{I}}
$$




$$
S O C=\left\{\begin{array}{l}
\operatorname{SOC}(t-1)(1-\mu)+\left(P_{P V}(t)+P_{w T}(t)-\frac{P_{L}(t)}{\eta^{t}}\right) \times \eta^{B}, P_{P V}(t)+P_{w T}(t)>P_{L}(t) \\
\operatorname{SOC}(t-1)(1-\mu)+\left(\frac{P_{L}(t)}{\eta^{I}}-P_{P V}(t)+P_{w T}(t)\right) \times \eta^{B}, P_{P V}(t)+P_{w T}(t)<P_{L}(t)
\end{array}\right.
$$

\subsection{Modeling of DPFC}

To transfer the actual power, the shunt and series controllers will be linked to the AC terminals of a transmission line [42]. The mean value of the product of non-sinusoidal current and voltage is used to calculate real power (see Figure 1). The cross-product of the integral parameters is 0 at various frequencies. The active power may be expressed as in the following (8)

$$
P=\sum_{i=1}^{\alpha} V_{i} I_{i} \cos \phi_{i}
$$

Since real power has no frequency dependency, it enhances the converter's mobility and capacity to create active power even in the absence of an electrical source, which is a benefit that at varying frequencies, the same strength may be consumed. Actual power must be received from the grid through a shunt converter operating at the fundamental frequency. At the harmonic standard, current must be injected into the grid through the distribution line. The high-pass filter allows for harmonic modules while disabling the portion of the frequency in DPFC that provides the harmonic components with a return path. The filter will harmonic current converters with a locked loop. In comparison, the DPFC's monitoring power is high because it comprises several converters of the smallrated set, the process is not impaired by the failure of one converter, showing no effect on the whole system while other converters must continue to contribute to the overall system's regular function. The appearance of the device is rendered more effective by bypass protection.

\subsection{Perturb and Observe MPPT}

MPPT approaches are often used to monitor maximum power from intermittent sources such as renewable energy sources. $\mathrm{P} \& \mathrm{O}$ is the most extensively used approach for producing duty pulses that are required to run the converter. It compares and monitors the reference voltages continually until the best value is reached. $\mathrm{P} \& \mathrm{O}$ is set at a relatively tiny size to guarantee little power loss. The sole disadvantage is that optimal power is not obtained under rapidly changing air conditions. The procedure described in Figure 3 is relatively simple and widely used. The suggested HRES system for PQ enhancement seen in Figure 4 is shown in the flow chart below. The next part, Section 3, has a full explanation of all of the modules. 


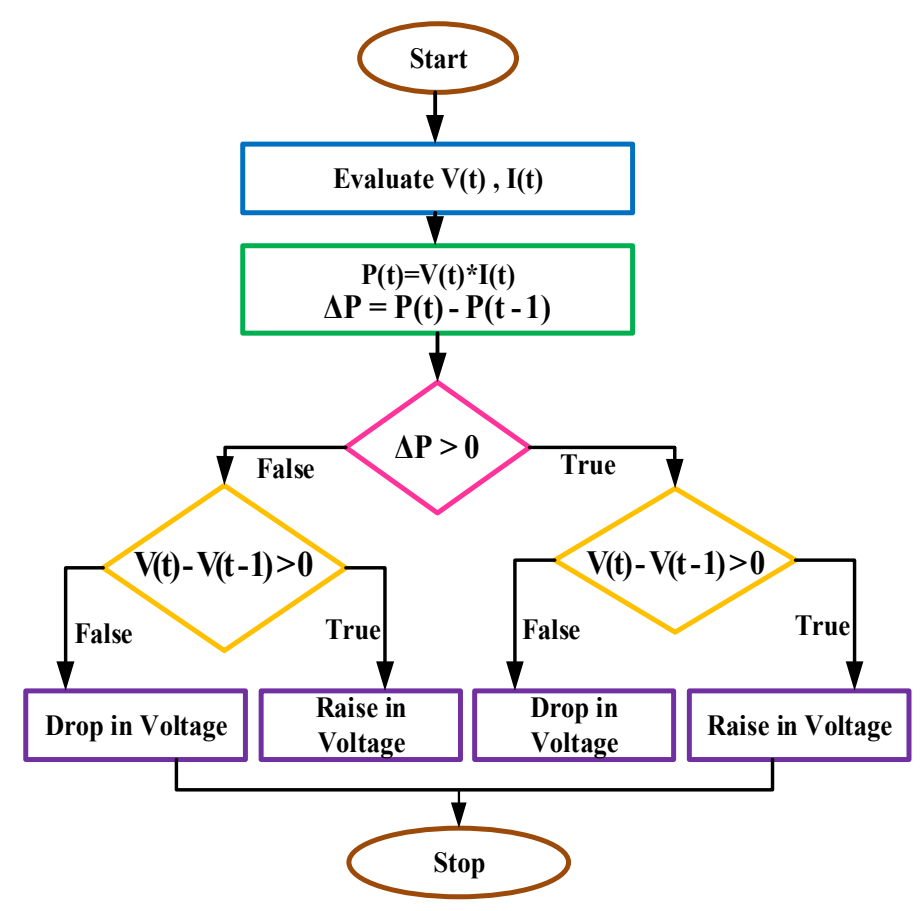

Figure 3. Perturb and observe MPPT [43].

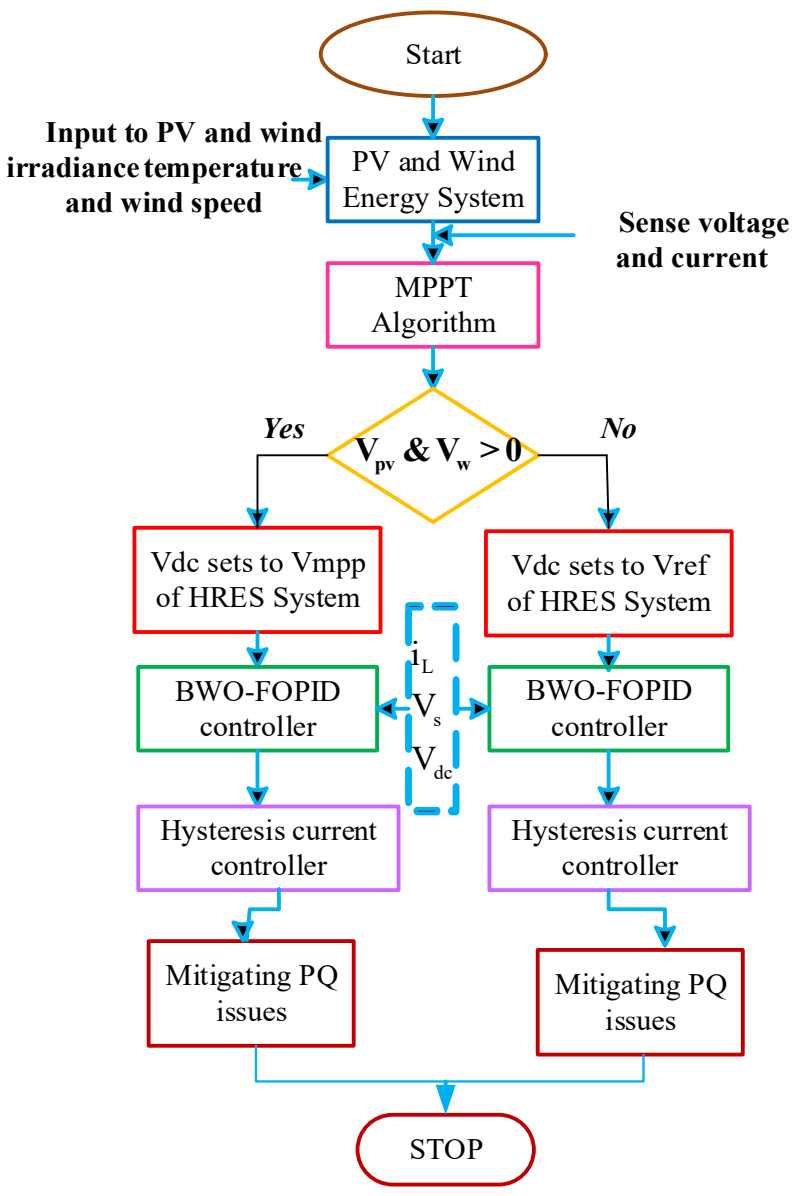

Figure 4. Flow chart of HRES system to mitigate PQ issues [44]. 


\section{Proposed Control Model of DPFC}

In this section, a HRES connected system with DPFC model is proposed. The control model of DPFC which includes series and shunt controllers are used to mitigate PQ issues. DPFC is operated with the use of a FOPID controller. The tuning of the FOPID controllers is done with BWO technique which obtains the best gain values. The series controller mitigates the current related problems and shunt controller is used to mitigate voltagerelated problems.

\subsection{Implementation of the Principle of Coordinated PQ in DPFC}

The DPFC consists of three basic controllers, as indicated in Figure 5 (e.g., central, series, and shunt controllers). Because it provides signals to the other controllers in the same device, the central controller is the primary controller in this system. At the same time, current harmonics are corrected for voltage using shunt and series controllers.

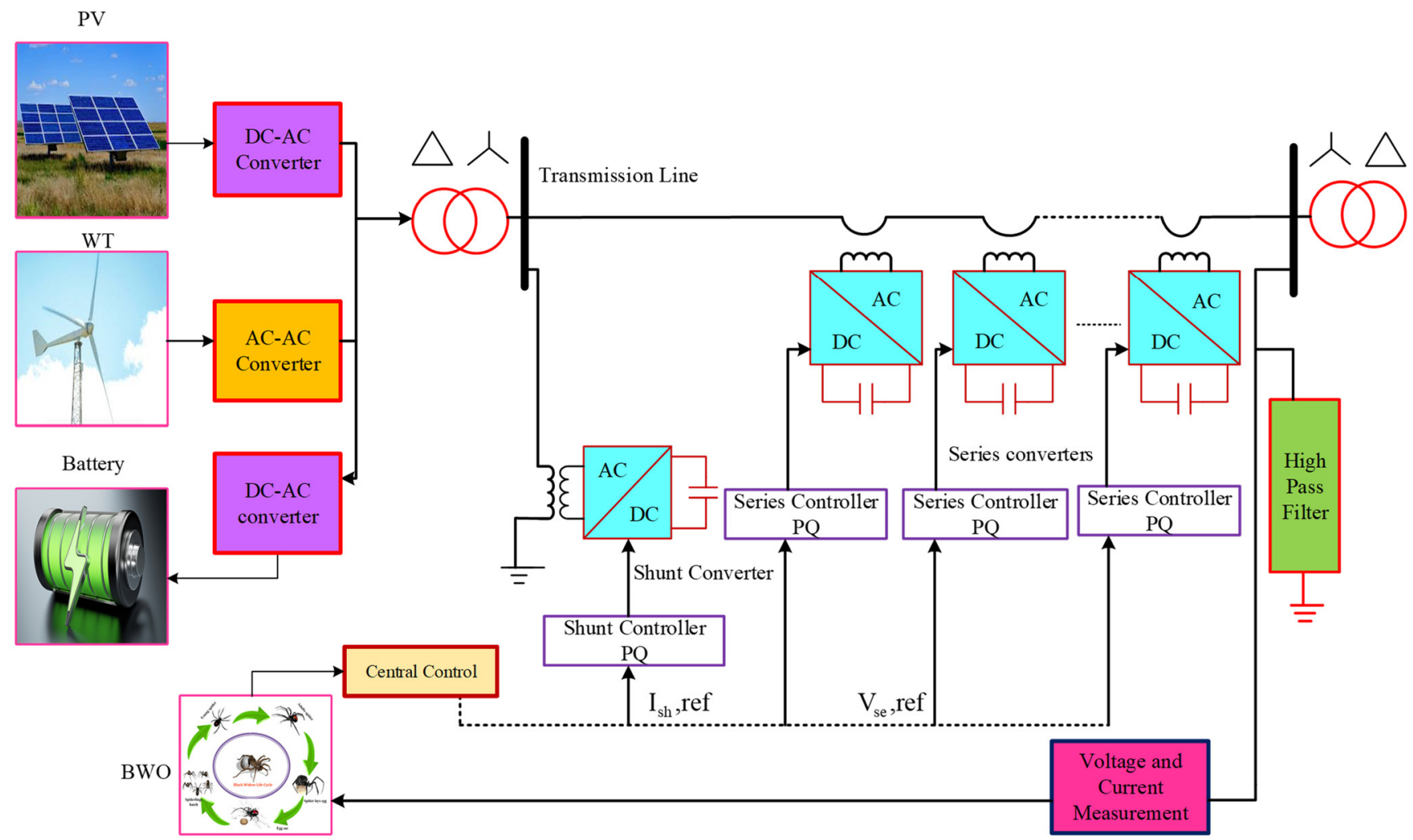

Figure 5. Proposed DPFC system.

\subsection{Central Control}

On several levels, it interacts with the DPFC characteristics (e.g., balancing of unbalanced components and power flow control). For the shunt and series controllers, a reference signal will be created. This satisfies the method's criteria by generating a reference to the series and shunt regulators, as well as voltage signals. The fundamental frequency will be used to create all of the reference voltage signals.

\subsection{Series Controller}

Figure 6 depicts the control process based on the series active power filter. The phase locked loop (PLL) is used to determine the reference voltage at first. The three-phase voltage measurement is converted into the $\mathrm{d}-\mathrm{q}$ axis using the $\mathrm{dq}$ transformation technique (Clarke transformation) [33]. The power filter was also employed in this manner to monitor the 
DPFC to tackle the system's power quality issues [45]. The mechanism of dq transformation from three-phase voltage is formally represented in Equation (9),

$$
\left[\begin{array}{l}
V^{0} \\
V^{d} \\
V^{q}
\end{array}\right]=\frac{2}{3}\left[\begin{array}{ccc}
\frac{1}{2} & \frac{1}{2} & \frac{1}{2} \\
\sin (\alpha t) & \sin \left(\alpha t-\frac{2 \pi}{3}\right) & \sin \left(\alpha t+\frac{2 \pi}{3}\right) \\
\cos (\alpha t) & \cos \left(\alpha t-\frac{2 \pi}{3}\right) & \cos \left(\alpha t+\frac{2 \pi}{3}\right)
\end{array}\right]\left[\begin{array}{c}
V^{a} \\
V^{b} \\
V^{C}
\end{array}\right]
$$

The $\mathrm{d}$ axis voltage is represented as a direct voltage as well as the alternating component voltage. The $\mathrm{d}$ axis voltage can be smoothing by the low-pass filter (LPF) which is mathematically formulated as (10),

$$
V^{d(d c)}=V^{d}-V^{d(a c)}
$$

After that, the voltage is changed into three phases (11), the voltage's hysteresis band is controlled using the control pulses which are calculated and tuned by FOPID with BWO. Similarly, the shunt active power filter with a control algorithm is presented in the following section.

$$
\left[\begin{array}{l}
V^{R a} \\
V^{R b} \\
V^{R c}
\end{array}\right]=\frac{2}{3}\left[\begin{array}{ccc}
\sin (\alpha t) & \frac{1}{2} & 1 \\
\sin (\alpha t) & \sin \left(\alpha t-\frac{2 \pi}{3}\right) & 1 \\
\cos (\alpha t) & \cos \left(\alpha t-\frac{2 \pi}{3}\right) & 1
\end{array}\right]\left[\begin{array}{c}
V^{d(d c)} \\
V^{q} \\
V^{o}
\end{array}\right]
$$

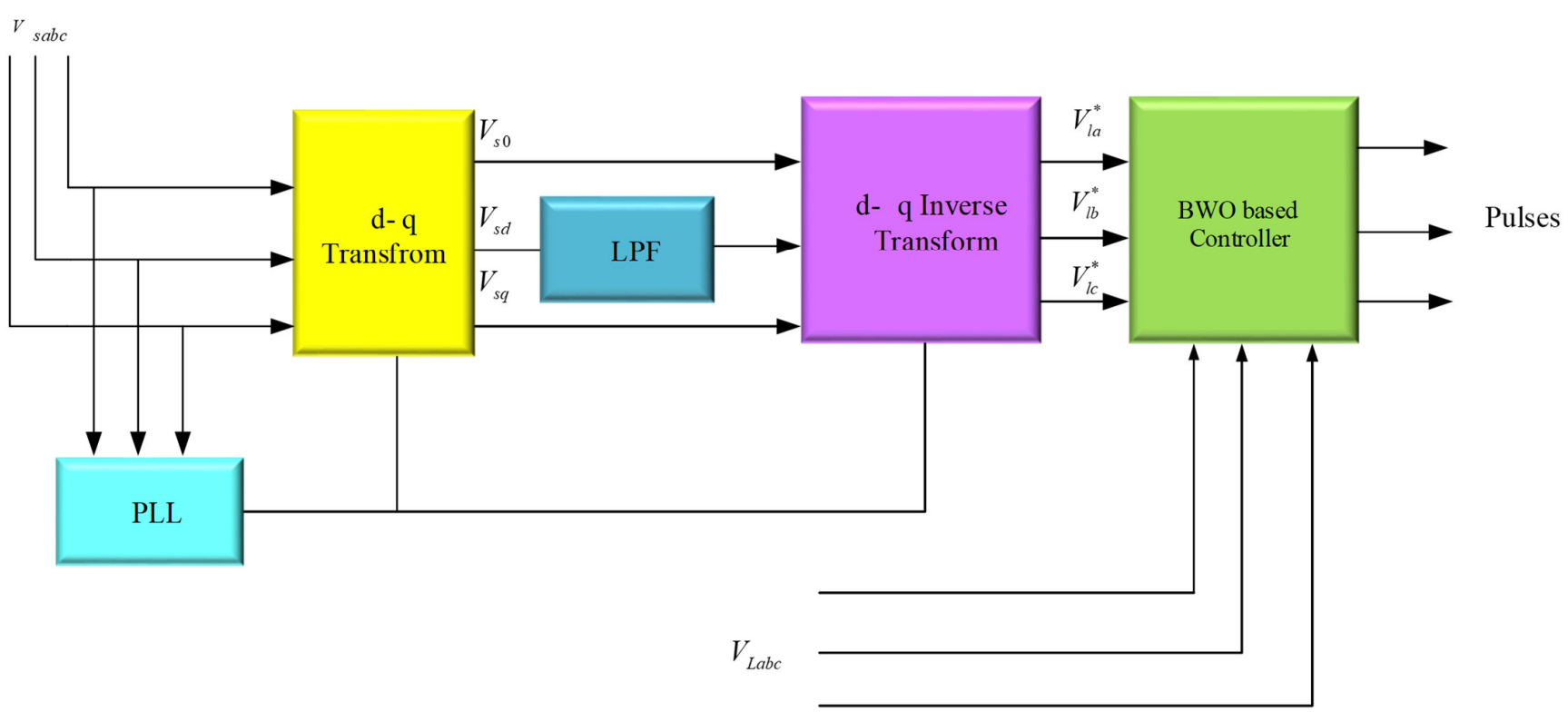

Figure 6. Series active filter controller.

\subsection{Shunt Active Power Filter Control Strategy}

The shunt active power filter control strategy with the proposed controller is illustrated in Figure 7. The three-phase currents and voltages are changed into $\alpha$ and $\beta$, which are described in the following Equations (12) and (13) [46,47]. Based on phase neutral voltages and load currents, the actual and unconsidered powers of instantaneous values are computed. In the shunt active filter, the real and reactive power is computed based on Equation (14)

$$
\left[\begin{array}{l}
V^{s 0} \\
V^{s \alpha} \\
V^{s \beta}
\end{array}\right]=\sqrt{\frac{2}{3}}\left[\begin{array}{ccc}
\frac{1}{\sqrt{2}} & \frac{1}{\sqrt{2}} & \frac{1}{\sqrt{2}} \\
1 & -\frac{1}{2} & -\frac{1}{2} \\
0 & \frac{\sqrt{3}}{2} & -\frac{\sqrt{3}}{2}
\end{array}\right]\left[\begin{array}{l}
V^{s a} \\
V^{s b} \\
V^{s c}
\end{array}\right]
$$




$$
\begin{gathered}
{\left[\begin{array}{c}
I^{l 0} \\
I^{l \alpha} \\
I^{l \beta}
\end{array}\right]=\sqrt{\frac{2}{3}}\left[\begin{array}{ccc}
\frac{1}{\sqrt{2}} & \frac{1}{\sqrt{2}} & \frac{1}{\sqrt{2}} \\
1 & -\frac{1}{2} & -\frac{1}{2} \\
0 & \frac{\sqrt{3}}{2} & -\frac{\sqrt{3}}{2}
\end{array}\right]\left[\begin{array}{l}
I^{L a} \\
I^{L b} \\
I^{L c}
\end{array}\right]} \\
{\left[\begin{array}{l}
P \\
Q
\end{array}\right]=\left[\begin{array}{cc}
V^{s \alpha} & V^{s \beta} \\
-V^{s \beta} & V^{s \alpha}
\end{array}\right]\left[\begin{array}{l}
I^{l \alpha} \\
I^{l \beta}
\end{array}\right]}
\end{gathered}
$$

After that, the reference currents are computed based on Equation (15)

$$
\left[\begin{array}{l}
I^{R a} \\
I^{R b} \\
I^{R c}
\end{array}\right]=\sqrt{\frac{2}{3}}\left[\begin{array}{cc}
1 & 0 \\
-\frac{1}{2} & \frac{\sqrt{3}}{2} \\
-\frac{1}{2} & -\frac{\sqrt{3}}{2}
\end{array}\right]\left[\begin{array}{l}
I^{R \alpha} \\
I^{R \beta}
\end{array}\right]
$$

Based on the $I_{\text {ref, }}$, the error current is computed which must be compensated with the FOPID controller with the BWO algorithm [48]. In the shunt active power filter, the optical pulses are selected and created on the error values of the system. The optimal pulses are generated with the help of the BWO algorithm. A detailed description of the FOPID controller with BWO optimization is presented in the sections below.

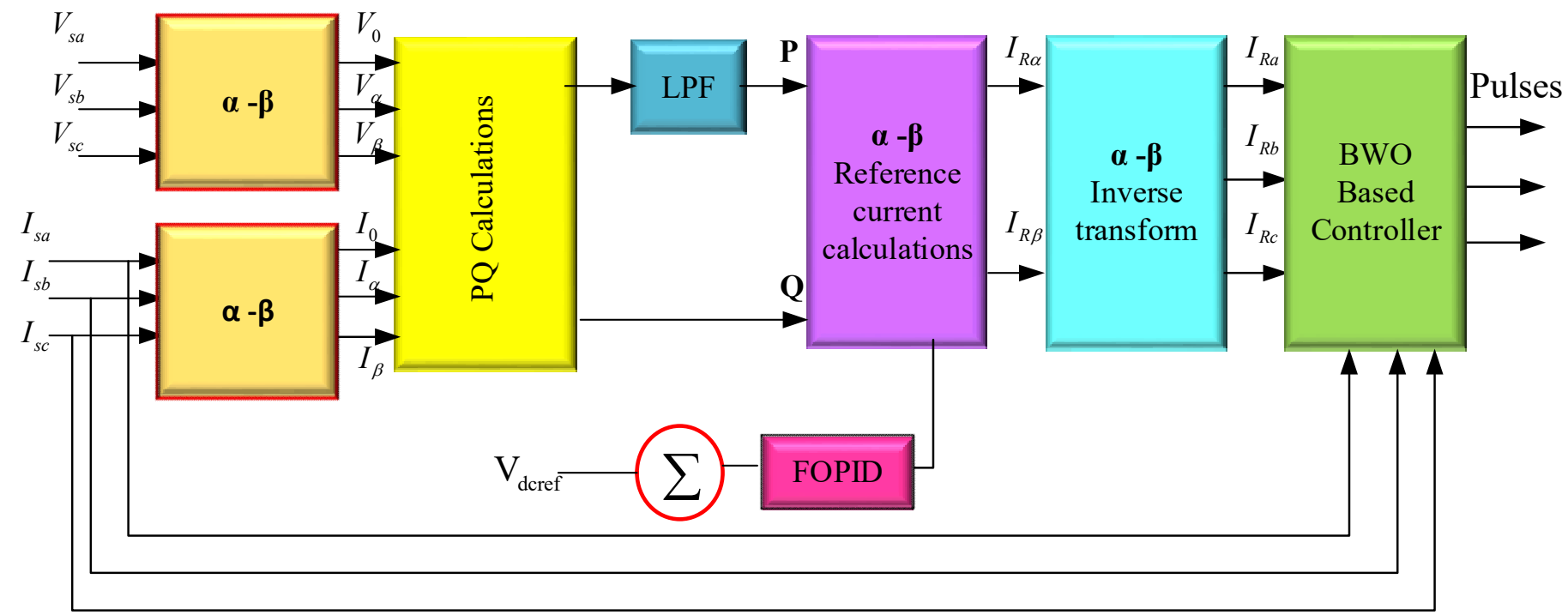

Figure 7. Shunt active filter controller.

\subsection{Strategies of DPFC Regulation}

The control structure plays a crucial length in identifying and strengthening DPFC's efficiency in minimizing the quality issues like sag, swell, and harmonics. Usage of this controller for the voltage and harmonics allows the problems arising in the power system to be investigated, recognized, and analyzed. The controller's management technique solves the PQ challenges on the distribution side by taking three steps: (1) The system voltage under fault conditions has to be recognized. (2) It is important to produce switching pulses for the operation of converters. (3) It should then produce the necessary reference voltage, which is required for modification purposes. DPFC incorporating PI, and FOPID controllers are used to alleviate PQ problems (e.g., sag, swell, and harmonics). A study of harmonics is also done for each controller [49].

\subsection{Regulation of DPFC}

This section will explain the PI controller for DPFC. By comparing the reference and actual voltage levels, the PI controller is used for producing the proper gate signals for the inverter's operation. Swell, sag, and other circumstances were created to test the PI 
controller's behavior. The PI controller's settings are tuned using BWO-based optimization. The DPFC controller is then activated to adjust for voltage swells and sags.

\subsection{DPFC with BWO}

A reference value is used to compute DC voltage in DPFC. As a consequence, the error is conveyed to the FOPID controller based on $\mathrm{BWO}$, which creates the required power to activate the series and shunt controllers [50]. The difference between the reference voltage $\left(V_{d c}\right)$ and the actual DC voltage is received by the FOPID controller $\left(V_{d c}\right)$. The error equation is as follows:

$$
E=V_{d c(r e f)}-V_{d c}
$$

\subsection{FOPID Controller}

Figure 8 depicts the basic FOPID diagram [51]. The e(s) error signal helps in the generation of the $\mathrm{u}(\mathrm{s})$ control output. FOPID is designed to reduce PQ issues caused by voltage and current changes in the HRES device with BWO tuning. The FOPID controller has five parameters which receives the best gain values which are listed in Table 2, are obtained when tuned with BWO techniques with set of instructions as listed in Table 3. The FOPID controller control signal is formally expressed as (17),

$$
u(s)=K_{p} E(s)+K_{i} \int E(S)+K_{d} \frac{d}{d t} E(s)
$$

The following steps are required during the design of the controller:

- $K_{P}$ is optimized for minimizing steady-state error and rise time

- $K_{d}$ is optimized for minimizing the settling time and overshoot

- $K_{\mathrm{i}}$ is optimized for eliminating the steady-state error

- $\quad s^{\lambda}$ and $s^{\mu}$ are fractional order parameters

Table 2. Gain values of FOPID.

\begin{tabular}{ccccc}
\hline $\mathbf{K}_{\mathbf{p}}$ & $\mathbf{K}_{\mathbf{i}}$ & $\mathbf{K}_{\mathbf{d}}$ & $\boldsymbol{\lambda}$ & $\boldsymbol{\mu}$ \\
\hline 49.426 & 29.750 & 0.3953 & 1 & 0.82 \\
\hline
\end{tabular}

Table 3. BWO parameters appendix.

\begin{tabular}{cc}
\hline Objective Function & Parameter Value \\
\hline Population size & 50 \\
\hline No of Iterations & 50 \\
\hline No of variables & 5 \\
\hline $\mathrm{K}_{\mathrm{p}}$ & 49.426 \\
\hline $\mathrm{K}_{\mathrm{i}}$ & 29.7500 \\
\hline $\mathrm{K}_{\mathrm{d}}$ & 0.3953 \\
\hline$\lambda$ & 1 \\
\hline$\mu$ & 0.82 \\
\hline
\end{tabular}




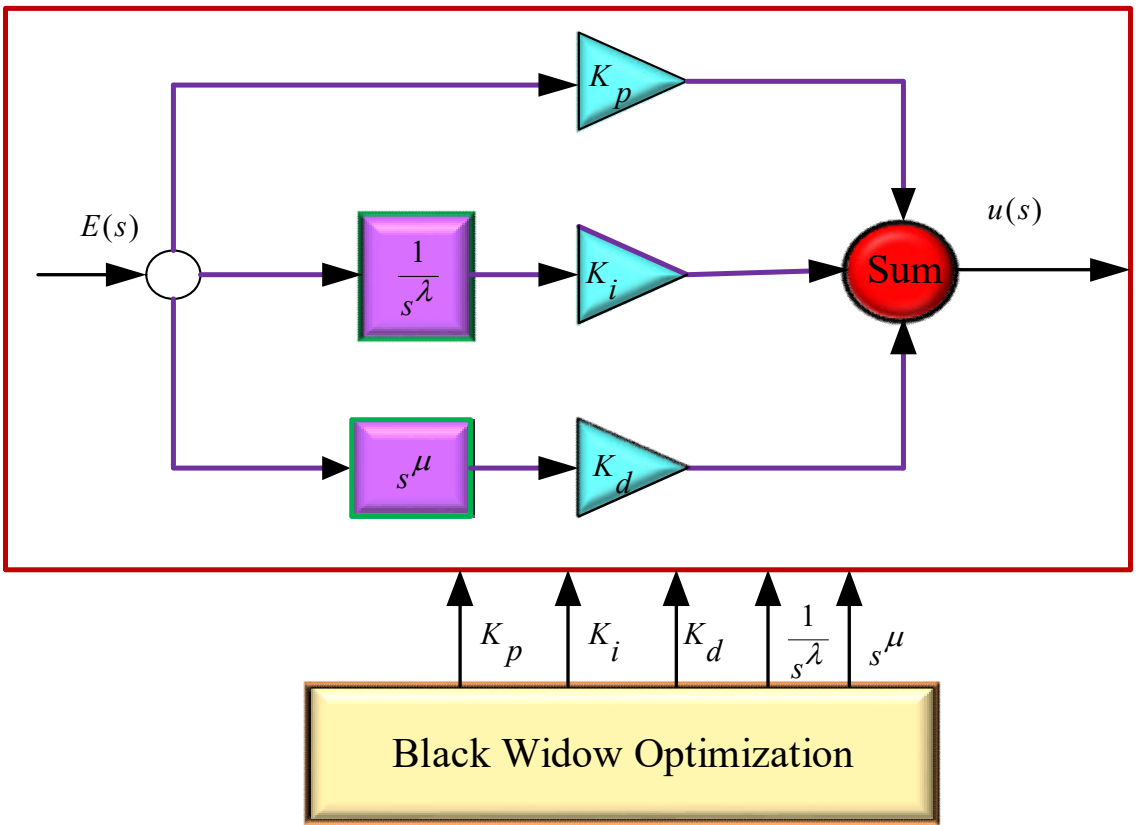

Figure 8. FOPID controller.

\subsection{Voltage Regulation Using BWO Optimization}

The controller's voltage source inverter (VSI) does not supply reactive power, has no reactive power, and should be utilized at steady state [52]. The primary aim here is to get FOPID optimal values, which result in extremely low DC voltage $\left(V_{d c}\right)$ dynamics. The ability to fine-tune FOPID to improve settling time and overshoot. This is accomplished using BWO optimization, which reduces the $V_{d c}$ variation from the reference $V_{d c}{ }^{*}$. The major factors that determine the optimality of FOPIDC are the rising time (tr), maximum overshoot $\left(V_{c} \max \right)$, and steady-state error (Ess) [53]. The major goal here is to reduce the dc voltage variation $\left(V_{d c}\right)$, which is expressed as

$$
\Delta V_{d c}=V_{d c}{ }^{*}-V_{d c}
$$

Equation (19) represents the objective function $(J)$ which is generally considered to be integral time absolute error (ITAE) which minimizes the error between $V_{d c}$ and $V_{d c}{ }^{*}$. With the use of the BWO technique, the best gain values of FOPID controller are obtained which results in low DC voltage $\left(V_{d c}\right)[54]$.

$$
J=\int_{0}^{t} t|e(t)| d t=\int_{0}^{t} t\left|V_{d c}-V_{d c(r e f)}\right| d t
$$

\section{Black Widow Optimization}

The BWO technique is illustrated in Figure 9. The proposed BWO technique generated the best gain parameters for the FOPID controller. BWO is an evolutionary algorithm that begins with the initialization of the population of spiders in which each spider is a possible solution. The initial population of spiders tries to reproduce the new generation in pairs. During or after mating, the female black widow consumes the male [55]. In her semen, they hold accumulated sperms and releases them into egg sacs. Spiderlings come out of the sacs as early as 11 days after being laid. For many days to a week, they cohabit on the maternal network, during this time sibling cannibalism is detected. Later they leave by being carried on the wind. 


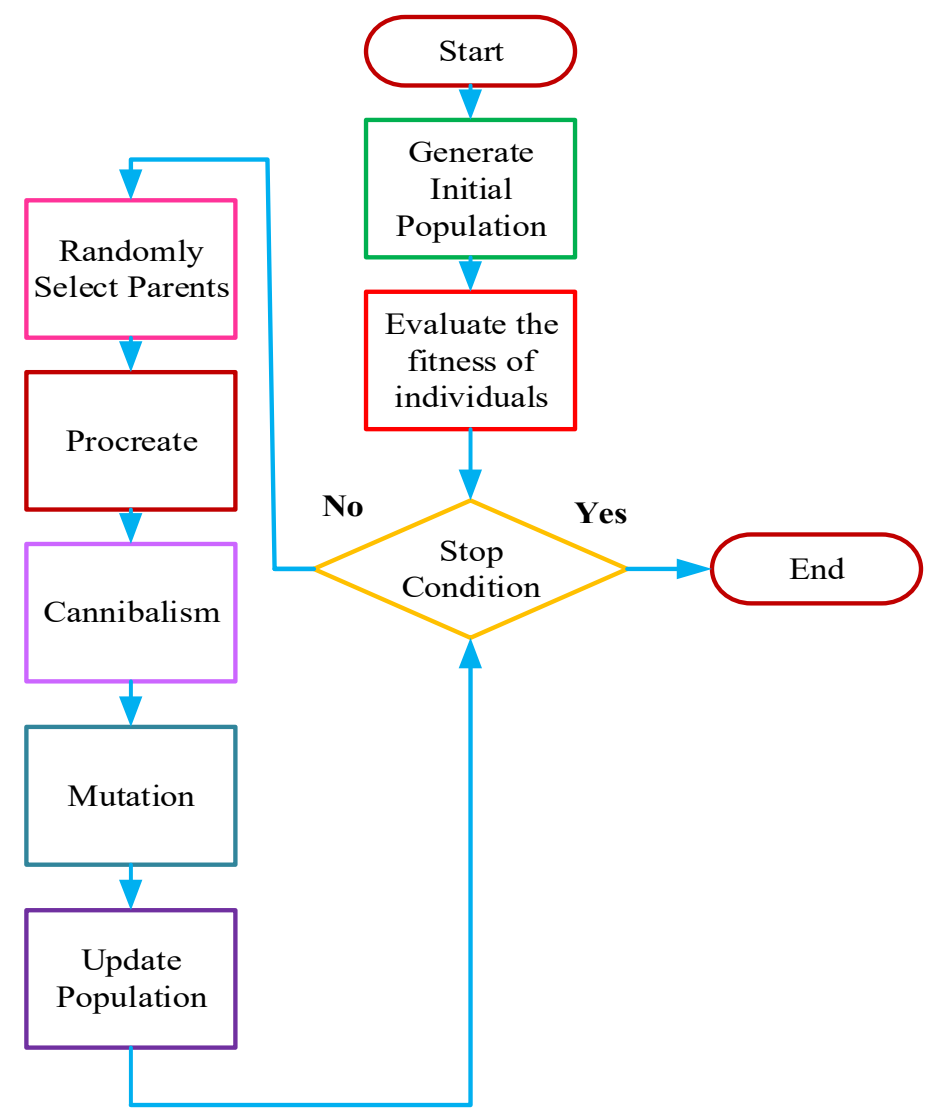

Figure 9. Flow chart of BWO optimization.

\subsection{Step 1: Initialize Population}

To solve an optimization problem, first, create an appropriate framework for resolving the current problem using the values of the problem variables. This structure is referred to as a "Chromosome" and a "Particle position" in GA and PSO methods, respectively. In BWO, it is referred to as "Widow." Each possible option is represented by a black widow spider that shows the problem variables' values. The structure should be seen as an array to solve benchmark functions in this work.

In a problem of Nvar-dimensional optimization, a widow is an array of $1 *$ Nvar, describing the problem's solution. Equation (20) defines the array as follows:

$$
\text { Widow }=\left[X_{1}, X_{2}, \ldots, X_{\text {Nvar }}\right]
$$

All the variable values $\left(\mathrm{X}_{1}, \mathrm{X}_{2}, \ldots, \mathrm{X}_{\mathrm{Nvar}}\right)$ are the floating-point number. The fitness of widow is obtained by evaluation of fitness function $f$ at a widow of $\left(X_{1}, X_{2}, \ldots, X_{N v a r}\right)$ So (21),

$$
\text { Fitness }=\mathrm{f}(\text { Widow })=\mathrm{f}\left(\mathrm{X}_{1}, \mathrm{X}_{2}, \ldots, \mathrm{X}_{\mathrm{Nvar}}\right)
$$

To begin with the optimization technique, a candidate matrix of widows with an initial spider population, the size $\mathrm{N}_{\text {pop }} \times \mathrm{N}_{\mathrm{var}}$ is created. Then we randomly choose pairs of parents to execute the procreation stage by mating, in which the female consumes the male black widow during mating.

\subsection{Step 2: Procreate}

The couples begin to mate and reproduce in the present generation since they are self-contained. Each pair mates autonomously from the others in nature. During each mating, around 1000 eggs are laid, with any larger spider babies surviving. This method might alternatively make use of an array named alpha. The offspring are produced using 
alpha, where $\mathrm{x} 1$ and $\mathrm{x} 2$ are parents and $\mathrm{y} 1$ and $\mathrm{y} 2$ are ancestors, as illustrated below, as long as the widow array is generated with random values (22).

$$
\begin{aligned}
& \mathrm{Y}_{1}=\operatorname{alphax}_{1}+(1-\text { alpha }) \mathrm{x}_{2} \\
& \mathrm{Y}_{2}=\operatorname{alphax}_{2}+(1-\text { alpha }) \mathrm{x}_{1}
\end{aligned}
$$

This procedure is continuously repeated for Nvar/2 times, with randomly chosen variables which should not be repeated. Finally, the infants and mothers are added to an array and categorized according to their health importance, now focused on a few of the best citizens which are applied to the newly produced population according to the cannibalism ranking. This procedure is applied to all the pairs.

\subsection{Step 3: Cannibalism}

In our world, there are three sorts of cannibalism. The first is sexual cannibalism, in which the black widow eats her partner while they are mating or immediately thereafter. Based on their fitness scores, we should be able to distinguish the female and male in this manner. The second kind of sibling cannibalism, in which the stronger spiderlings consume the weaker siblings. In this method, we create a cannibalism rating (CR) ranking, from which the number of survivors is calculated. In circumstances when the newborn consumes its mother, the third kind of cannibalism occurs. We utilize the fitness value of little spiderlings to estimate high fitness value.

\subsection{Step 4: Mutations}

At this point, we randomly pick the number of people from the population. As Figure 10 reveals, each of the choices selected two items in the sequence is shared at random. The evaluation of mutation decides Mutepop.

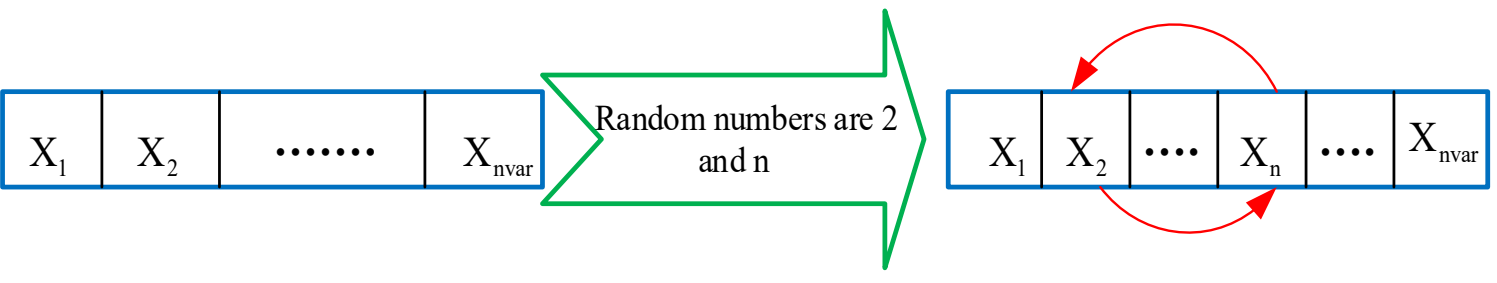

Figure 10. Mutation.

\subsection{Step 5: Convergences}

Compared to the other most evolutionary techniques, here three-stop requirements can also be considered: (a) the number of predefined iterations; (b) observance in conformity with several iterations, no improvement in the fitness value of the best widow; (c) achieving the degree of precision mentioned. BWO would be extended to some benchmarks in the next segment. Since optimal results are known in advance for benchmark functions, thereby we can achieve a defined degree of accuracy standard. The maximum sum of iteration is often set as a stop as well.

\subsection{Step 6: Setting Parameters}

To produce vest results with the proposed BWO technique requires certain parameters like rate of procreation (PP), cannibalism rate $(\mathrm{CR})$, and the rate of mutation $(\mathrm{PM})$. The chosen values in this paper for these parameters are seen in Table 3.The parameters should be changed accordingly to boost the algorithm's efficiency in obtaining the best results. The more the number of parameters is tuned, the greater the probability of jumping out of every optimal and greater local capability to find them in the search space globally. Consequently, the correct set of parameters that regulate the equilibrium between exploitation and exploration should be assured. The proposed algorithm has three controlling 
parameters, PP, CR, and PM. The number is PP in procreation, which defines how many persons are interested in procreation. By monitoring the output, further diversification is given by separate offspring which gives more opportunities to more specifically analyze the quest space. The cannibalism operator's control parameter, the CR, excludes the community from the wrong persons. By adjusting the needed value for this parameter, great efficiency for the exploitation step may be ensured by changing the quest agents from the local to the global stage and vice versa. PM denotes the percentage of people who are involved. In mutation, the appropriate value for this parameter should be employed to ensure that the duration between exploitation and exploration is balanced. This parameter may monitor the transition of the quest agents from the global level to the state and local level and drive them to the correct decision.

\subsection{Step 7: Stop}

The following step-by-step procedure repeats until the final optimal pulses are generated by the proposed FOPID controller

\section{Results and Discussion}

In this section, the performance of the proposed method is validated and analyzed. The proposed method for mitigating PQ issues in grid-connected HRES has been developed. The main aim is to increase the system's reliability by minimizing problems with the quality of electricity. There are drawbacks to the current methods that were listed in Section 4. So, with the aid of the proposed controller and DPFC, the efficiency of the system is enhanced. Here, the proposed method will include the current and voltage regulations in integrated HRES using DPFC with the proposed controller. Based on voltage, current, and fault conditions such as sag, swell voltage distortion, and harmonics with THD, the HRES grid-connected device with the suggested controller is evaluated. The FOPID parameters are evaluated with and without the system's PQ problems. In MATLAB/Simulink with the processor, the predicted method is executed on a computer with the following specifications: Intel(R) Core(TM) i5-3570S CPU @ $3.10 \mathrm{GHz}$, and the presentation is analyzed. The projected technique is compared with twelve techniques P\&O, PSO, Cuckoo, GA, GSA, $\mathrm{BBO}$, Whale, ESA, RFA, ASO, EVORFA, and BWO with existing PI controller techniques. The criteria for implementation are presented in Table 4.

Table 4. Implementation parameters.

\begin{tabular}{|c|c|}
\hline Parameters & Ratings \\
\hline \multicolumn{2}{|c|}{ PV } \\
\hline Irradiance & $1000 \mathrm{~W} / \mathrm{m}^{2}$ \\
\hline Diode resistance & $595.5 \Omega$ \\
\hline Forward voltage & $0.8 \mathrm{~V}$ \\
\hline \multicolumn{2}{|c|}{ Wind } \\
\hline Base torque & $8500 \mathrm{~N} / \mathrm{m}$ \\
\hline Nominal mechanical output power & $80 \mathrm{~kW}$ \\
\hline The base power of the electrical generator & $80 \mathrm{~kW} / 0.9$ \\
\hline Base wind speed & $12 \mathrm{~m} / \mathrm{s}$ \\
\hline Base rotational speed & $0.4 \mathrm{~m} / \mathrm{s}$ \\
\hline Stator phase resistance & $1.5 \Omega$ \\
\hline Armature inductance & $8.5 \mathrm{e}-3 \mathrm{H}$ \\
\hline \multicolumn{2}{|c|}{ Grid } \\
\hline $\mathrm{V}_{\mathrm{Ph}}$ (Phase Voltage) & $550 \mathrm{~V}$ \\
\hline Frequency & $50 \mathrm{~Hz}$ \\
\hline \multicolumn{2}{|c|}{ Load } \\
\hline Nominal voltage & $550 \mathrm{~V}$ \\
\hline Real power & $1000 \mathrm{e}-3 \mathrm{~W}$ \\
\hline
\end{tabular}


The proposed technique is verified in the system using PQ concerns like sag, swell, disturbance, and harmonics. The PQ difficulties are compensated by delivering ideal shunt and series active power filter pulses with the help of the BWO-FOPID controller, which ideally regulates the PQ issues using the DPFC and the needed suggested shunt and series active power filter controller [56]. The DPFC will supply the required power to mitigate the PQ issues and adjust for load demand in the system. In the proposed HRES system, the DPFC configuration is employed to deliver critical power and mitigate PQ concerns. PV and WT systems can generate enough power to fulfill the load demand, which is considered the system's major source of electricity [57]. The WT and PV may be impacted by external influences that may be mitigated by factors including the MPPT approach in the device [58]. The DPFC system uses the generated electricity to counter load demand and mitigate PQ issues in the system. The DPFC system is compatible with a grid-connected load scheme. Evaluation of the predicted design structure is done under the three failure circumstances of sag, swell, voltage, disturbance, as well as the device's signal harmonic levels. Three different examples are utilized to assess the device output; these scenarios are explained below.

Case 1: Analysis of HRES during constant irradiance and wind speed

Case 2: Analysis of HRES during variable irradiance and wind speed

Case 3: Condition for voltage sag and current sag

Case 4: Condition for voltage and current swell

Case 5: Condition for voltage and current disturbances

The five cases are individually analyzed with the design parameters of voltage, current, power, and injected power from the DPFC.

Case 1: Analysis of HRES during constant and variable inputs

Here in this case HRES performance is simulated under constant irradiance and wind speed of PV and wind. The input to the PV is set to $1000 \mathrm{~W} / \mathrm{m}^{2}$ and WT velocity to $12 \mathrm{~m} / \mathrm{s}$ to compensate for the load demand in the system. From Figure 11 we can observe the power produced with the PV and WT sources is $31 \mathrm{~kW}$ and $80 \mathrm{~W}$. Thus, the generated power is transferred to meet the load demand. When surplus energy is generated it can be stored in the battery and can be used under critical conditions. Figure 12 shows the battery requirements for SOC and battery capacity

Case 2: Analysis of HRES during variable irradiance and wind speed

From Figure 13 we can observe the analysis of HRES simulated under variable irradiance and wind speed. The produced power of PV is modified depending on the variance of irradiance since irradiance is directly proportional to the generated power. The power produced by PV is increased if irradiance is increased. Similarly, the pace of WT is increased, as well as the power produced by WT. The analysis of HRES is shown in Table 3.

Case 3: Condition for voltage and current sag

For the stable and linear operation of the device, the voltage sag has to be eliminated. The DPFC is used to provide the necessary power to fulfill the demand for loads and eliminate PQ problems. DPFC designed is used to mitigate the PQ issues related to both voltage and current sag under fault conditions with the proposed controller. The series and shunt active power filters are playing an important role to balance the current and voltage in the HRES system.

In the proposed HRES interface grid-connected system, a three-phase fault has been created. Due to this fault, there is a sudden reduction of voltage and current is observed which is generally termed to be sag. To overcome this condition the proposed DPFC and the controller is designed to operate with the use of the FOPID controller. The optimal pulse is generated using the BWO technique which is used to eliminate the PQ problem and compensate load demand. During a three-phase fault at $t=0.75 \mathrm{~s}$ to $\mathrm{t}=0.85 \mathrm{~s}$, voltage sag of $200 \mathrm{~V}$ is observed as shown in Figure 14a. The sag is then eliminated with the injected voltage of $300 \mathrm{~V}$ which can be seen in Figure 14b. From Figure 14c the load voltage after elimination of voltage sag can be observed. Similarly, during $t=0.75 \mathrm{~s}$ to $0.85 \mathrm{~s}$, current 
sag is observed under fault conditions. Figure 15a shows the current decrease during sag of about $0.2 \mathrm{~A}$. Figure $15 \mathrm{~b}$ shows the injected current of $1.8 \mathrm{~A}$ and Figure $15 \mathrm{c}$ shows the compensated load current of $2 \mathrm{~A}$.

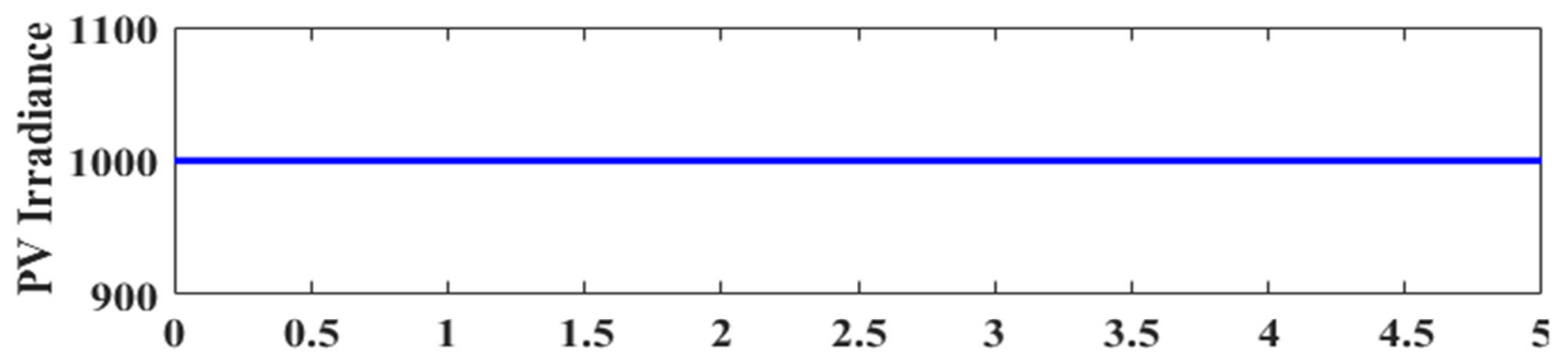

(a)

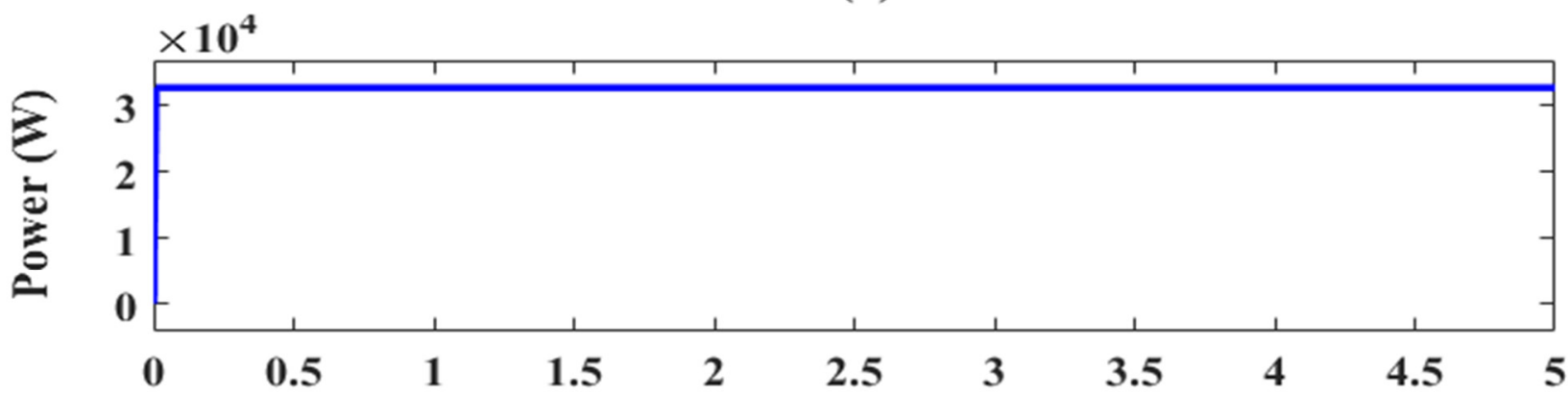

(b)
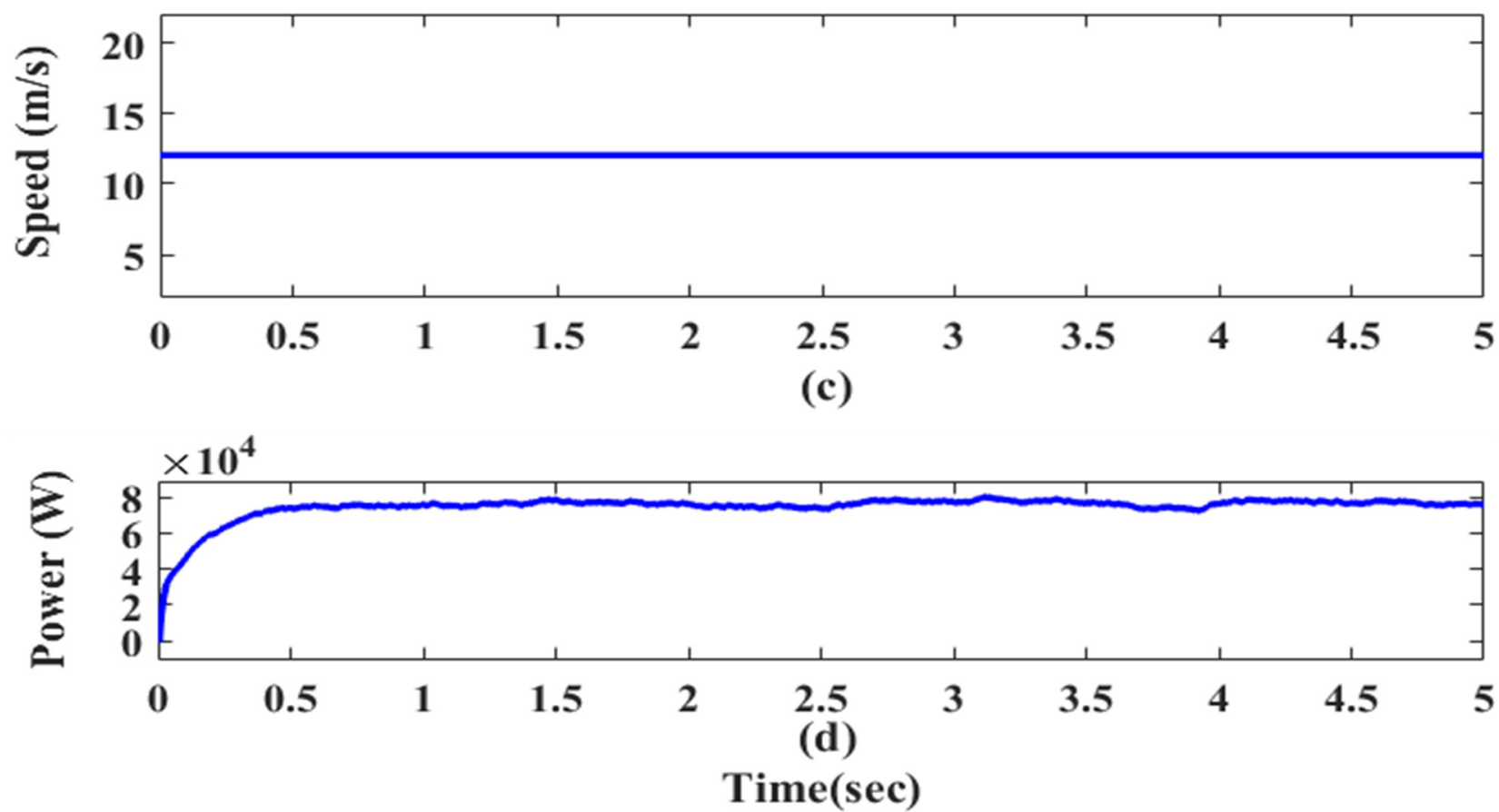

Figure 11. Performance under constant HRES conditions: (a) PV irradiance, (b) PV power, (c) wind speed, and (d) wind power. 

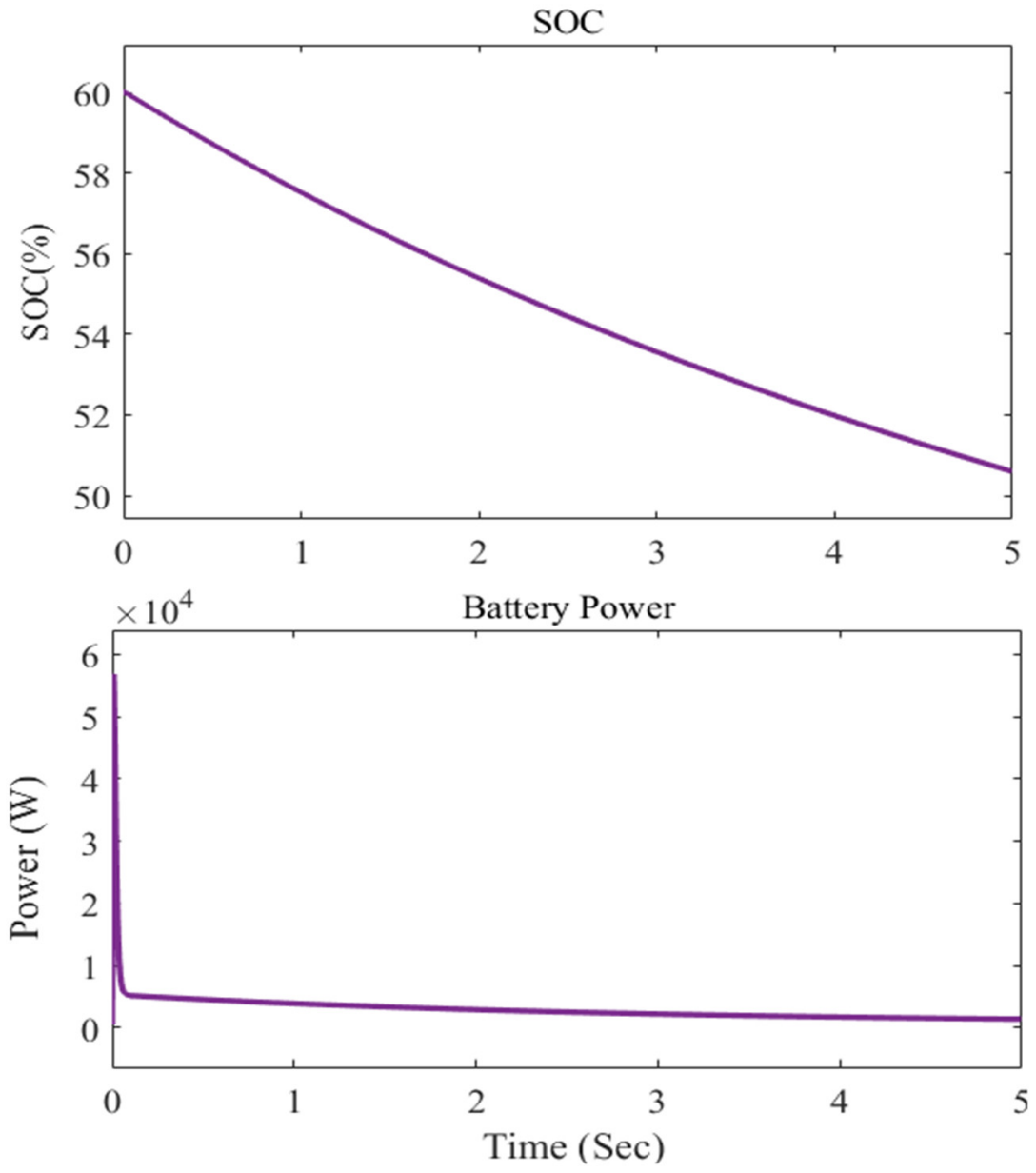

Figure 12. Analysis of battery power.

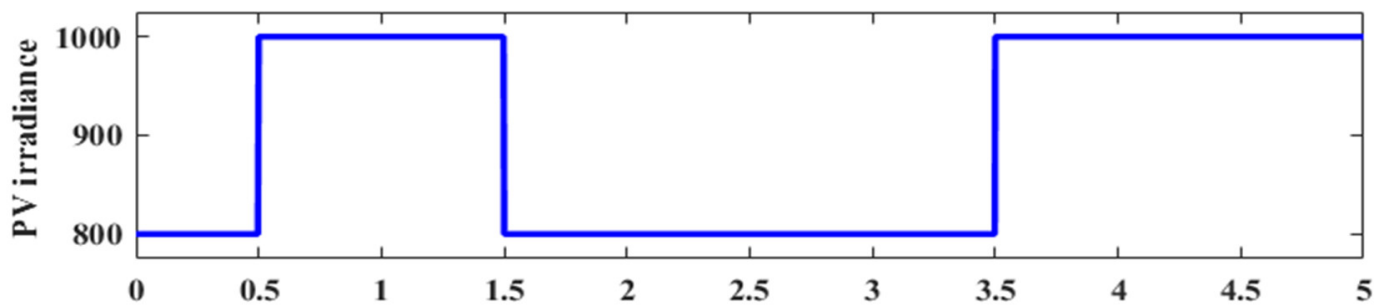

(a)

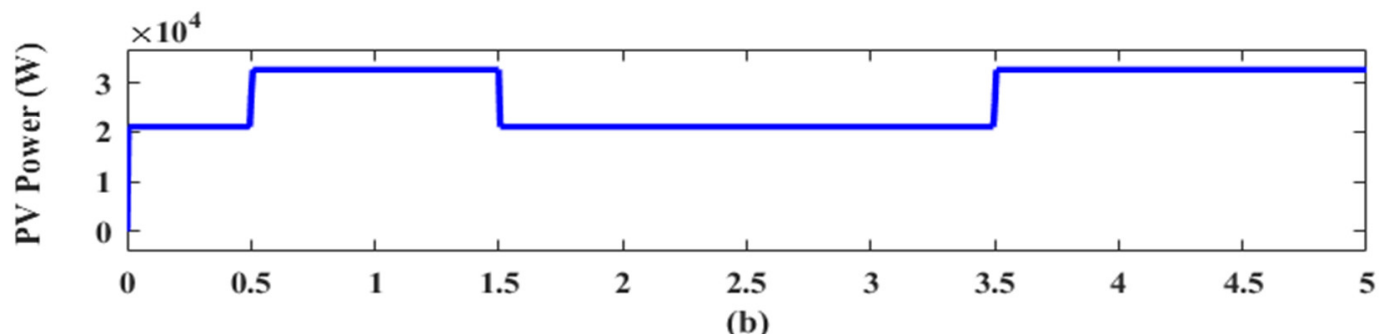

Figure 13. Cont. 


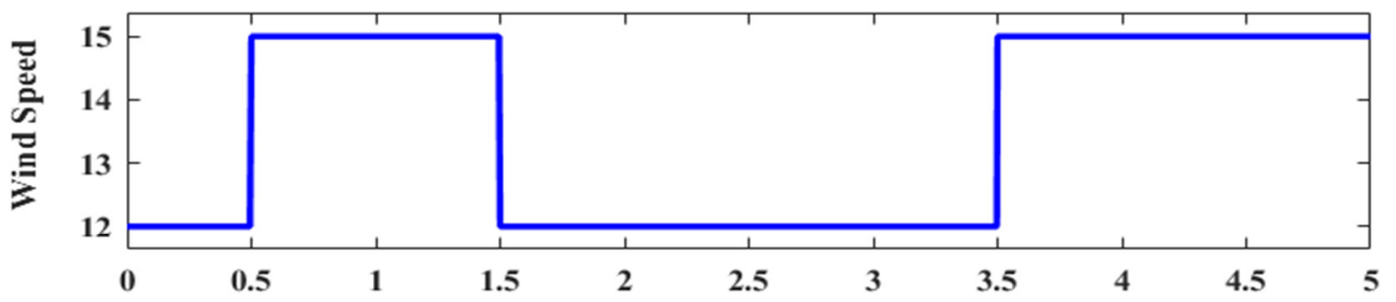

(c)

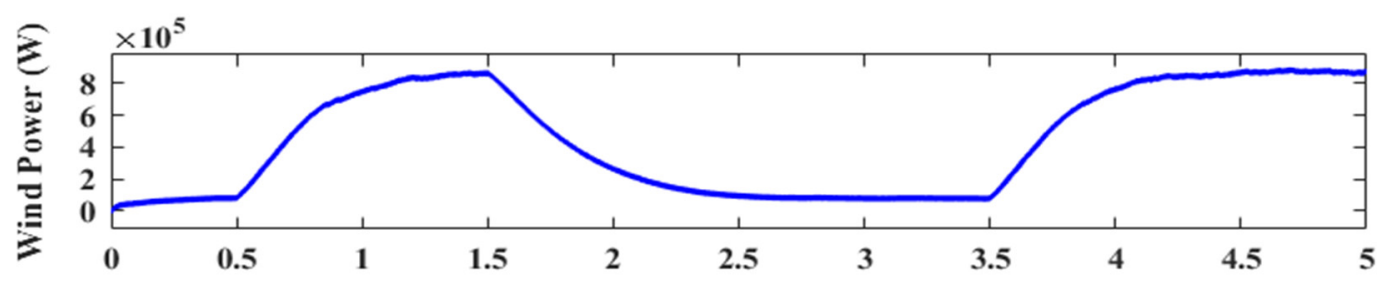

(d)

Time (sec)

Figure 13. Performance under variable HRES: (a) PV irradiance, (b) PV power, (c) wind speed, and (d) wind power.
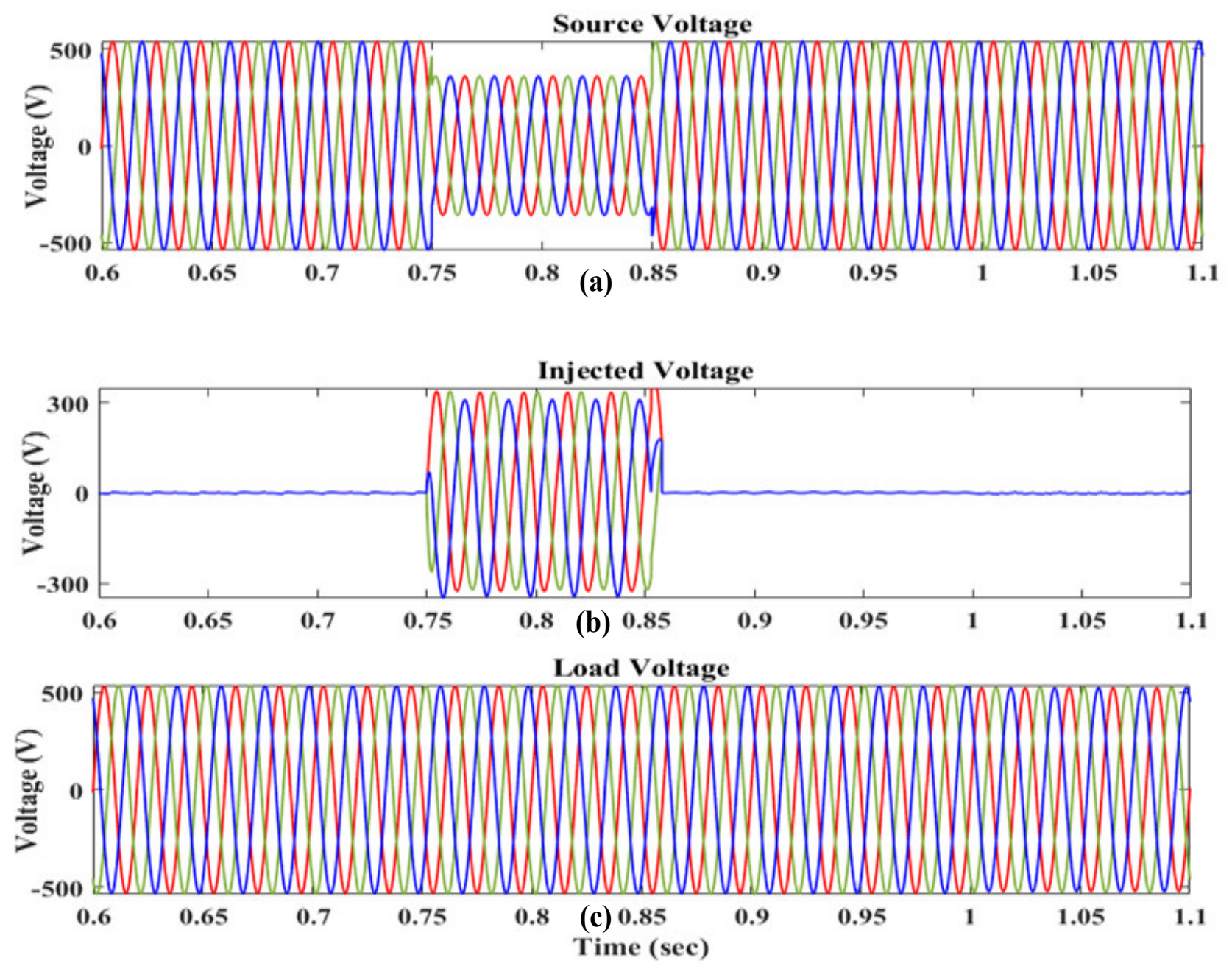

Figure 14. Performance under voltage sag: (a) source voltage (b), injected voltage, and (c) load voltage. 


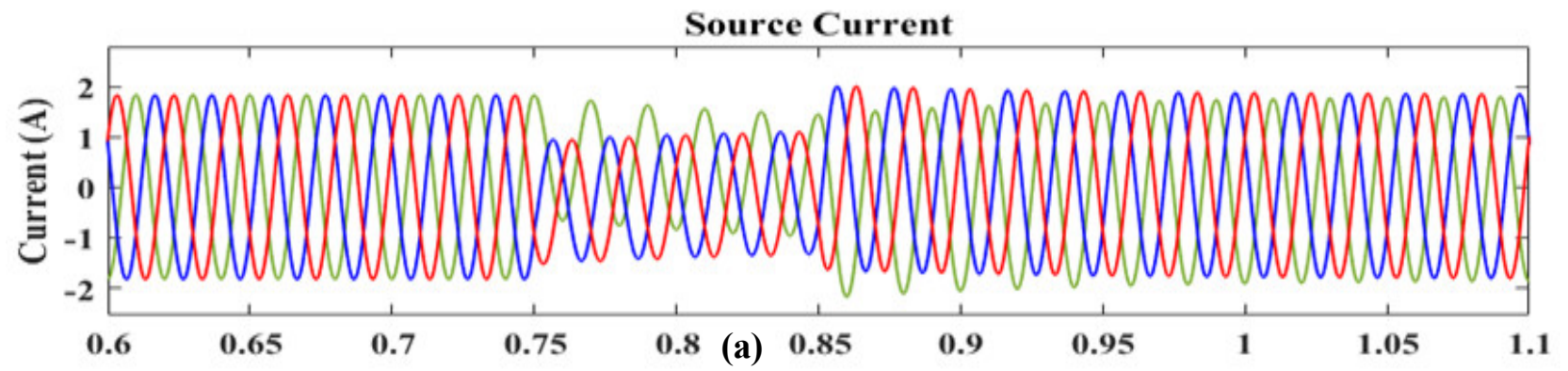

Injectedcurrent

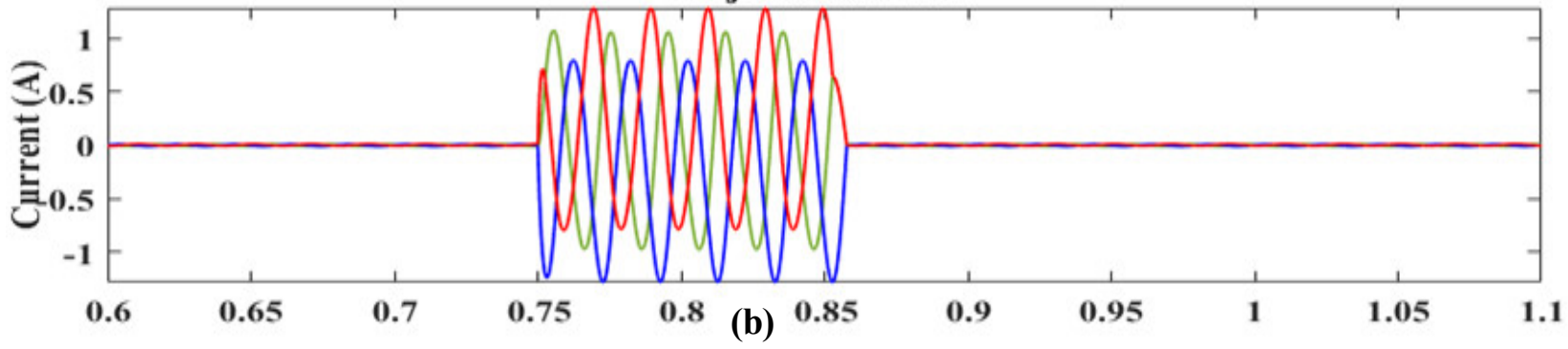

Load current

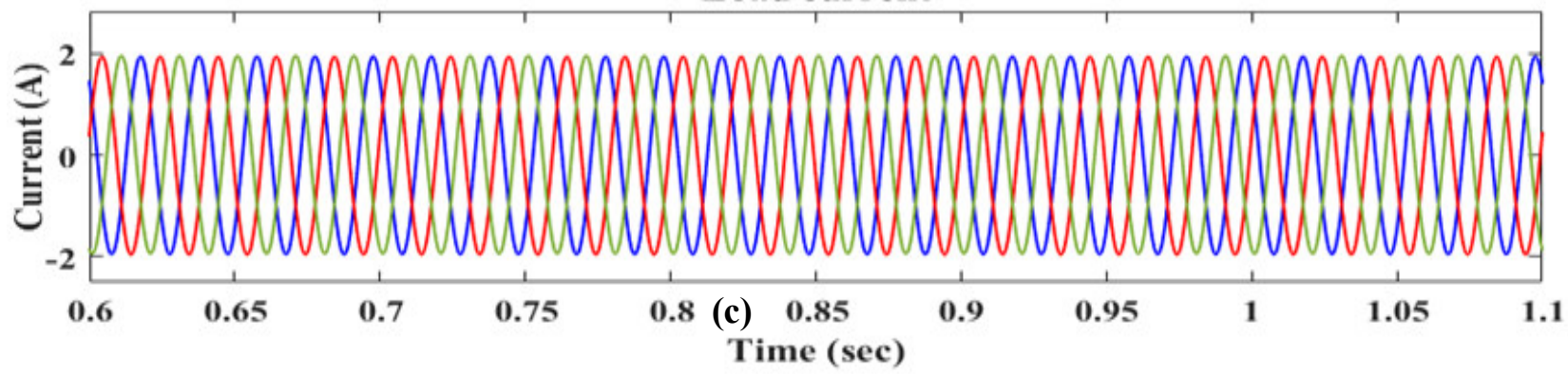

Figure 15. Performance under current sag: (a) source current, (b) injected voltage, and (c) load voltage.

Case 4: Condition for voltage and current swell

In the proposed HRES interface grid-connected system, a three-phase fault has been created. Due to this fault, there is a sudden increase of voltage and current is observed which is generally termed swell. The swell is characterized as an increased voltage and current concerning reference voltage and current. For the constant operation in the network, the swell produced under fault conditions must be eliminated using the suggested controller. To overcome this condition, the proposed DPFC and the controller is designed to operate with the use of the FOPID controller. The optimal pulse is generated using the BWO technique which is used to eliminate the PQ problem and compensate load demand. During a three-phase fault at $t=0.75 \mathrm{~s}$ to $t=0.85 \mathrm{~s}$, a voltage swell of $100 \mathrm{~V}$ is observed as shown in Figure 16a. The swell is then eliminated with the absorption voltage of $100 \mathrm{~V}$ which can be seen in Figure 16b. From Figure 16c the load voltage after elimination of voltage swell can be observed. Similarly, during $t=0.75 \mathrm{~s}$ to $0.85 \mathrm{~s}$, current swell is observed under fault conditions. Figure 17a shows the current increase during sag of about 1.8 A. Figure 17b shows the absorbed current of $1.8 \mathrm{~A}$ and Figure $17 \mathrm{c}$ shows the compensated load current of $2 \mathrm{~A}$ with the assistance of the suggested controller. The PQ problems, and load demand targets are accomplished. To calculate the right error values by choosing optimum device values, the series, and shunt active power filters with FOPID controller-based BWO are primarily involved. In the segment below, the voltage disruption situations are evaluated. 
Case 5: Condition for voltage and current disruptions

Normally, signal distortion happens as a result of the non-linear load relationship. When a non-linear load is introduced to the load side, the impact of voltage changes in the network is instantly established. The suggested controller is meant to adjust for load demand and PQ difficulties in the device, allowing the HRES device to have a continuous impact. The proposed effect is designed to provide for safe working and PQ problems reduction in the HRES framework under non-linear load, essential load, and unbalanced load situations. The BWO is utilized to offer the optimal gain settings of the FOPID controller to reduce the error value of the $\mathrm{V}_{\text {ref }}$ and $\mathrm{I}_{\text {ref }}$ in the signals. The suggested controller would correct for load demand and PQ problems in the HRES framework resulting from a variety of research scenarios. It is compared to previously devised methodologies to validate the proposed system evaluation. The anticipated system's comparative analysis is detailed in the related unit.

From Figure 18a we can observe the variation in three-phase voltages during $\mathrm{t}=0.75 \mathrm{~s}$ to $t=0.85 \mathrm{~s}$. Figure $18 \mathrm{~b}$ shows the voltage difference is then corrected with the use of FOPID controller operating series controller of the DPFC which is mainly used to correct the voltage-related issues. In Figure 18c we can observe the load voltage after mitigating the disturbances. Similarly, in Figure 19a we can observe the variation in current from $t=0.75 \mathrm{~s}$ to $\mathrm{t}=0.85 \mathrm{~s}$ due to the sudden changes in load. Figure $19 \mathrm{~b}$ shows the current has been corrected using the FOPID controller using shunt controller which is used to mitigate the problems related to current. Figure $19 \mathrm{c}$ shows the load current after mitigation.
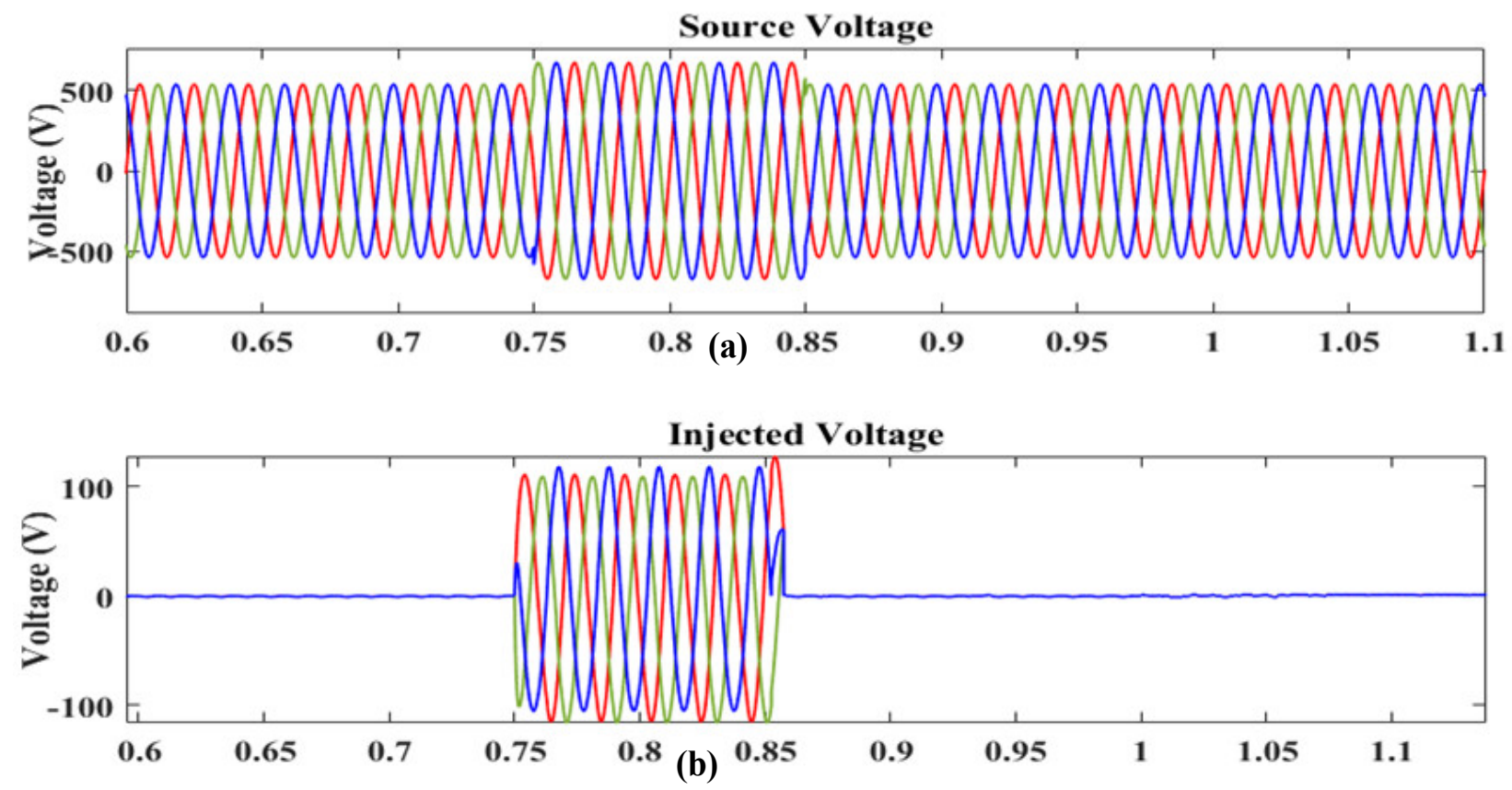

Load Voltage

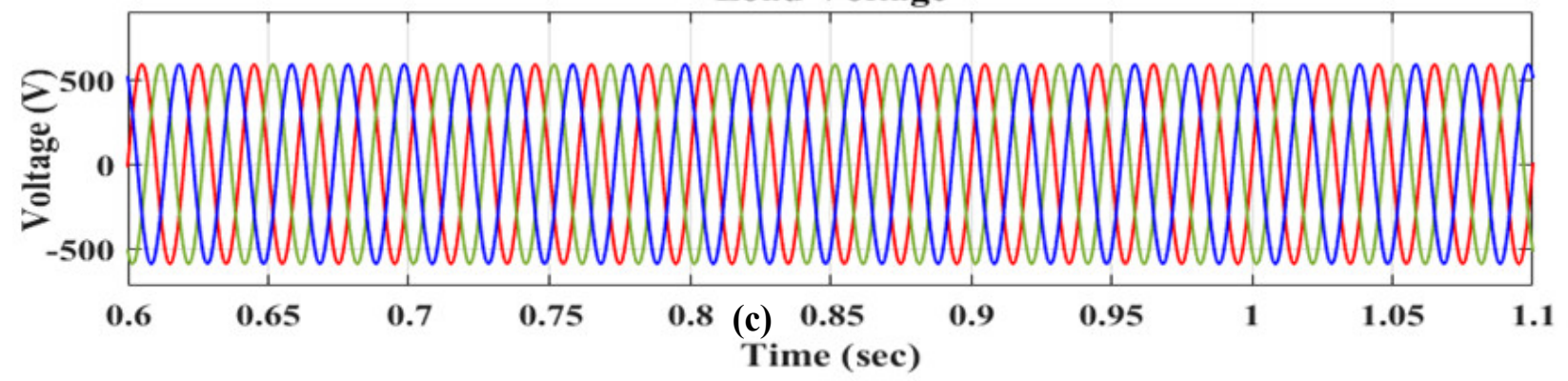

Figure 16. Performance under voltage swell: (a) source voltage, (b) injected voltage, and (c) load voltage. 

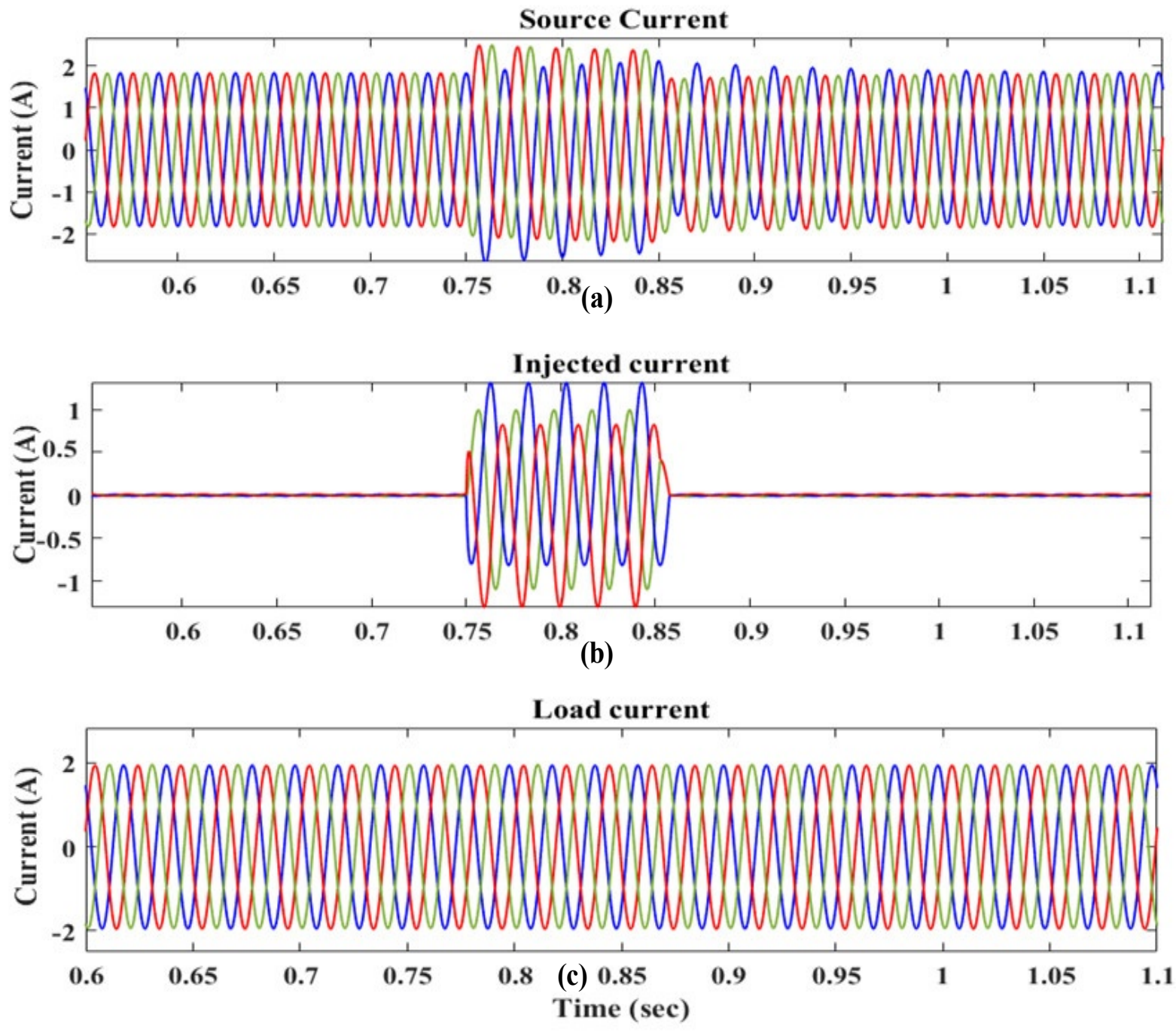

Figure 17. Performance under current swell: (a) source current, (b) injected current, and (c) load current.
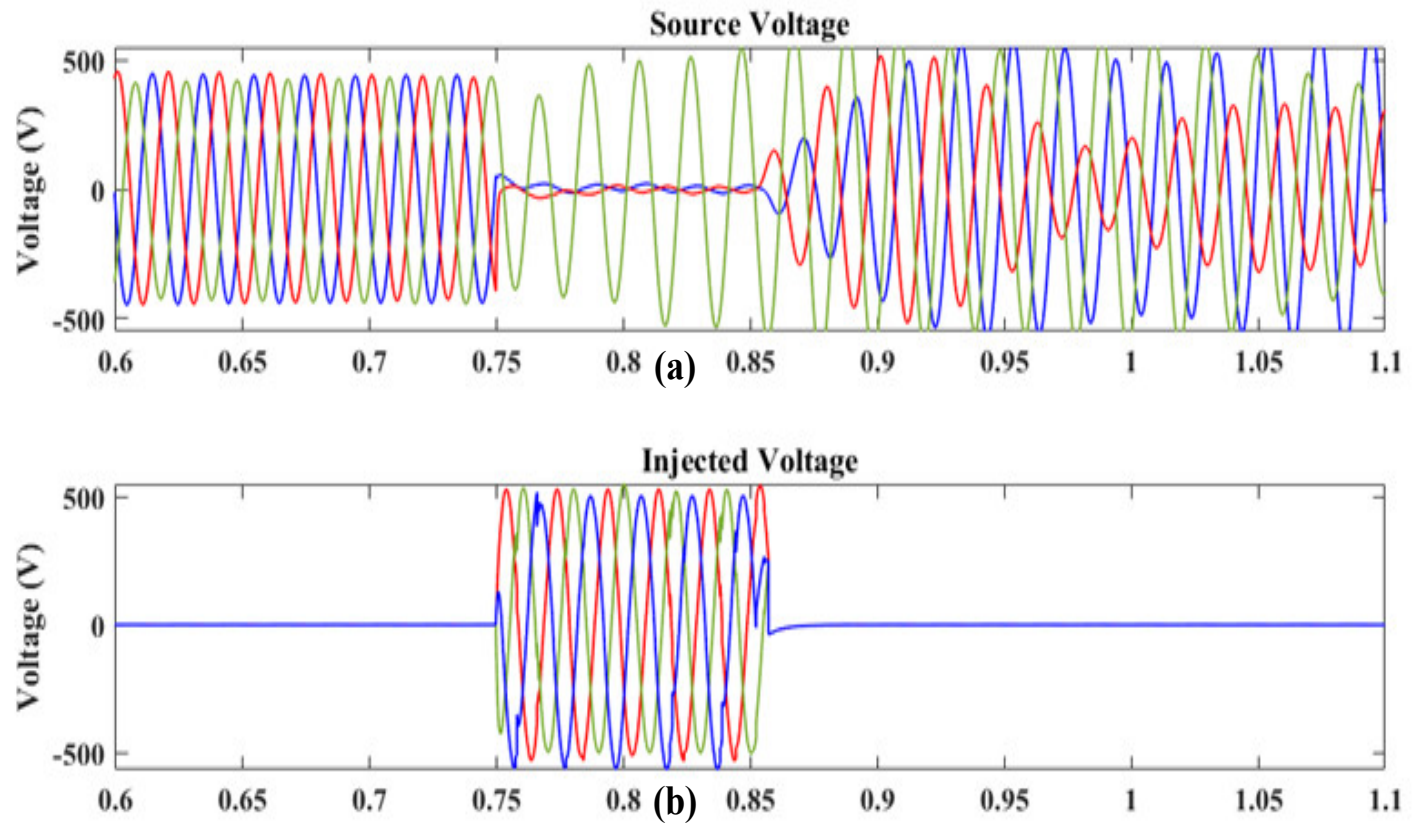

Figure 18. Cont. 


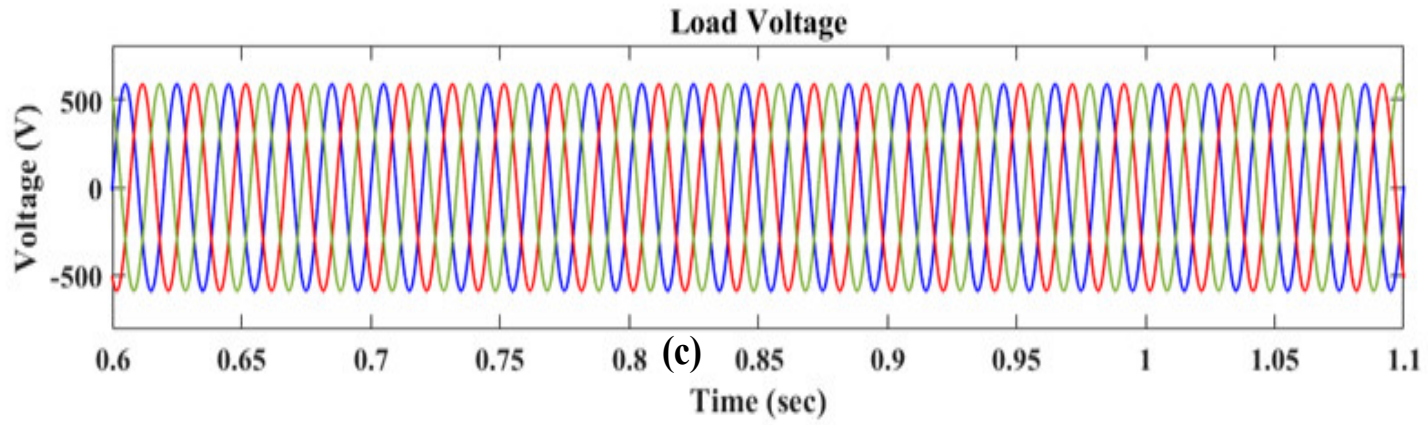

Figure 18. Performance under voltage disruptions: (a) voltage disturbance, (b) injected voltage, and (c) load voltage.

Source Current

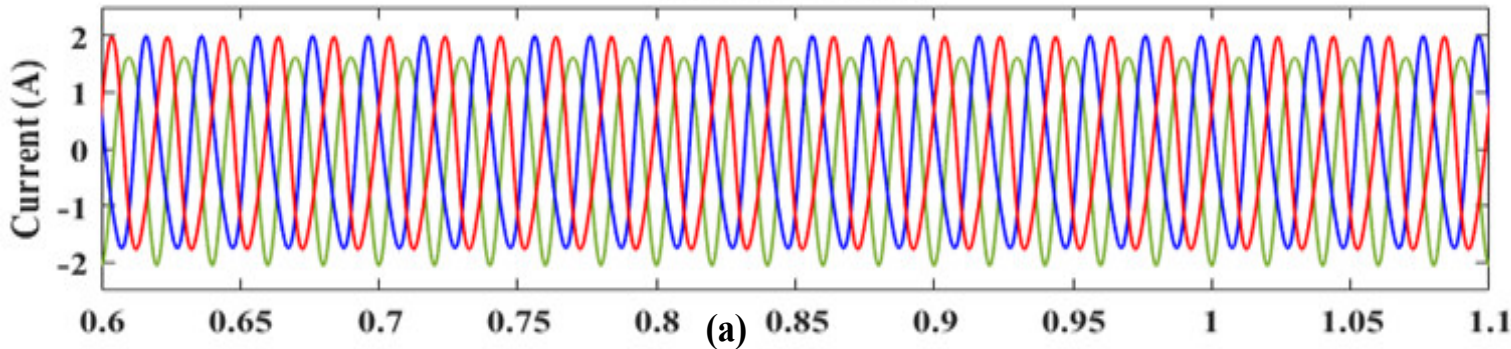

Injected Current

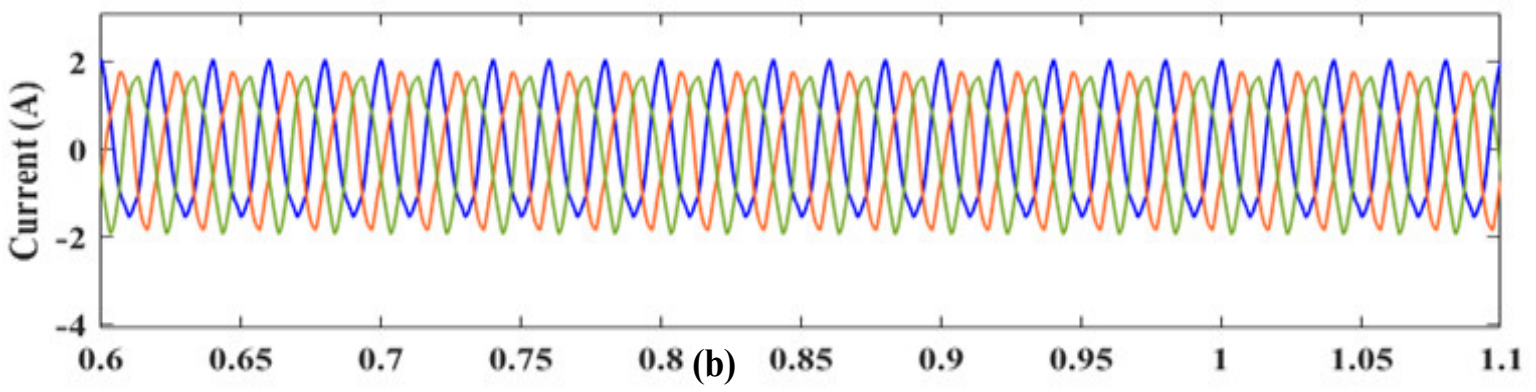

Load current

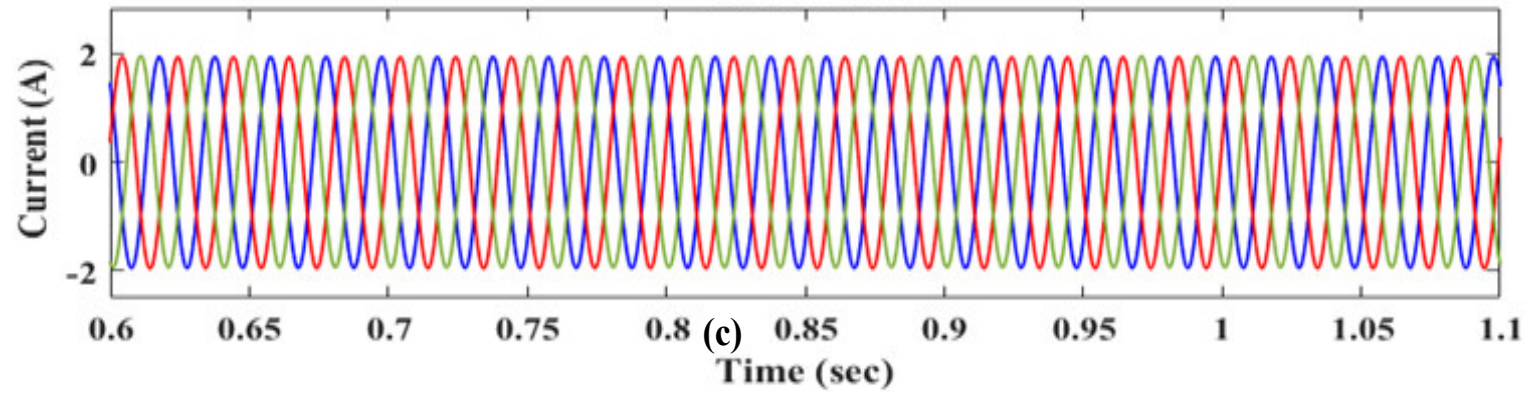

Figure 19. Performance under current disruptions: (a) source current, (b) injected current, and (c) load current.

\section{Comparison Analysis}

PQ issues in the HRES integrated system are analyzed with the use of the FOPIDbased BWO technique with DPFC address issues like sag, swell, disruptions, and THD reduction. The FOPID controller is optimized with the proposed technique and compared with various existing methods, and we have proven that the proposed technique gives the best results. In this section, the results from Figure 20 represent the comparative analysis of HRES powers. In Figure 21a a real power comparison and Figure $21 \mathrm{~b}$ reactive power comparison can be seen which is compared with PI controller, PSO, Cuckoo, GA, GSA, 
BBO, Whale, ESA, RFA, ASO, EVORFA, and BWO. Figure 22a depicts THD analysis before compensation and after compensation. Figure 22b shows the THD analysis of various existing methods. The proposed HRES integrated system with BWO controller reduced the THDs, which falls within the limits of IEEE 519 standards. Table 5 provides the THD analysis before DPFC and Table 6 after DPFC.

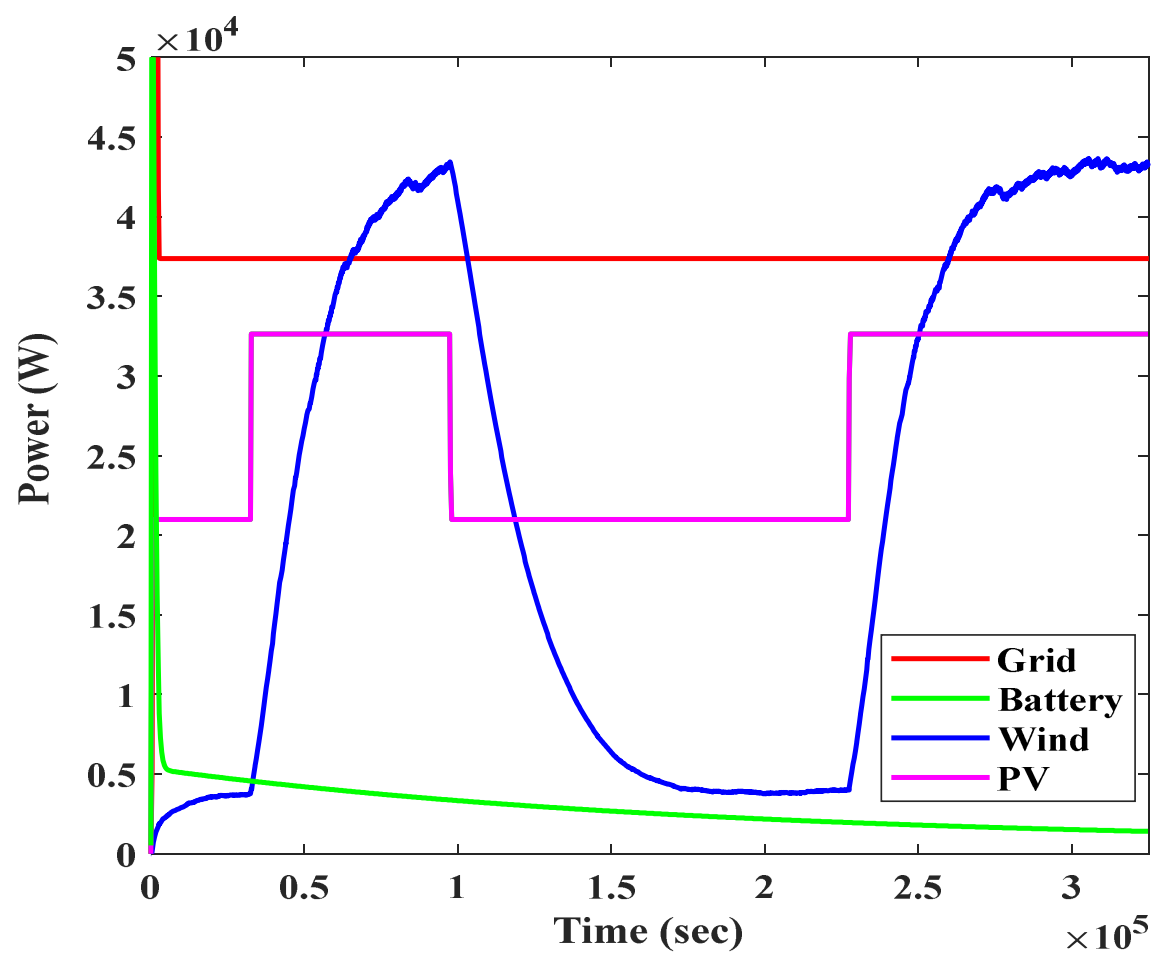

Figure 20. Comparative analysis of HRES power.

Table 5. THD analysis before DPFC.

\begin{tabular}{|c|c|c|c|c|c|c|c|c|c|c|}
\hline \multirow{2}{*}{ S. No. } & \multirow{2}{*}{ Techniques } & \multicolumn{9}{|c|}{ Before DPFC } \\
\hline & & 5 & 7 & 11 & 13 & 17 & 19 & 23 & 25 & 29 \\
\hline 1 & Proposed & 26.5 & 31.10 & 25.11 & 50.46 & 20.02 & 10.91 & 20.34 & 10.19 & 6.34 \\
\hline 2 & EVORFA & 48.58 & 32.03 & 35.87 & 50.85 & 25.04 & 12.66 & 20.63 & 10.36 & 6.47 \\
\hline 3 & ASO & 52.06 & 40.18 & 40.15 & 50.91 & 30.04 & 13.78 & 20.67 & 10.39 & 6.22 \\
\hline 4 & RFA & 53.98 & 42.26 & 41.31 & 50.95 & 39.05 & 14.84 & 20.69 & 10.40 & 7.19 \\
\hline 5 & ESA & 56.06 & 43.35 & 42.47 & 50.98 & 40.04 & 16.92 & 20.73 & 10.42 & 8.23 \\
\hline 6 & Whale & 57.04 & 48.40 & 43.52 & 50.99 & 40.04 & 17.95 & 20.74 & 10.42 & 8.99 \\
\hline 7 & $\mathrm{BBO}$ & 58.30 & 51.44 & 45.65 & 51.02 & 41.05 & 18.99 & 20.75 & 10.43 & 8.36 \\
\hline 8 & GSA & 60.73 & 52.54 & 48.85 & 51.06 & 42.05 & 24.07 & 20.78 & 10.45 & 8.59 \\
\hline 9 & GA & 63.37 & 57.65 & 52.05 & 51.11 & 43.05 & 26.16 & 20.82 & 10.47 & 8.92 \\
\hline 10 & Cuckoo & 66.25 & 59.77 & 56.28 & 51.16 & 44.05 & 26.26 & 20.85 & 10.49 & 8.37 \\
\hline 11 & PSO & 69.41 & 62.90 & 58.54 & 51.22 & 46.06 & 27.37 & 20.91 & 10.52 & 8.96 \\
\hline 12 & PI & 76.72 & 63.21 & 60.12 & 51.35 & 48.06 & 28.62 & 20.99 & 10.57 & 8.64 \\
\hline
\end{tabular}


Table 6. THD analysis after DPFC.

\begin{tabular}{|c|c|c|c|c|c|c|c|c|c|c|}
\hline \multirow{2}{*}{ S. No. } & \multirow{2}{*}{ Techniques } & \multicolumn{9}{|c|}{ After DPFC } \\
\hline & & 5 & 7 & 11 & 13 & 17 & 19 & 23 & 25 & 29 \\
\hline 1 & Proposed & 2.92 & 0.20 & 0.38 & 0.08 & 0.004 & 0.16 & 0.06 & 0.03 & 2.44 \\
\hline 2 & EVORFA & 4.58 & 0.12 & 0.23 & 0.05 & 0.003 & 0.09 & 0.04 & 0.02 & 1.47 \\
\hline 3 & ASO & 5.03 & 0.21 & 0.40 & 0.08 & 0.004 & 0.17 & 0.07 & 0.04 & 2.53 \\
\hline 4 & RFA & 5.21 & 0.22 & 0.42 & 0.09 & 0.004 & 0.17 & 0.067 & 0.04 & 2.62 \\
\hline 5 & ESA & 5.40 & 0.23 & 0.43 & 0.09 & 0.004 & 0.19 & 0.07 & 0.04 & 2.72 \\
\hline 6 & Whale & 5.61 & 0.23 & 0.45 & 0.098 & 0.005 & 0.19 & 0.07 & 0.04 & 2.82 \\
\hline 7 & $\mathrm{BBO}$ & 5.83 & 0.24 & 0.46 & 0.10 & 0.005 & 0.20 & 0.08 & 0.043 & 2.94 \\
\hline 8 & GSA & 6.07 & 0.25 & 0.48 & 0.11 & 0.01 & 0.21 & 0.08 & 0.05 & 3.06 \\
\hline 9 & GA & 6.37 & 0.27 & 0.51 & 0.11 & 0.005 & 0.22 & 0.08 & 0.05 & 3.20 \\
\hline 10 & Cuckoo & 6.63 & 0.28 & 0.53 & 0.12 & 0.006 & 0.23 & 0.09 & 0.05 & 3.34 \\
\hline 11 & PSO & 6.94 & 0.30 & 0.55 & 0.123 & 0.006 & 0.24 & 0.09 & 0.05 & 3.50 \\
\hline 13 & PI & 7.67 & 0.32 & 0.61 & 0.13 & 0.006 & 0.26 & 0.099 & 0.05 & 3.86 \\
\hline
\end{tabular}

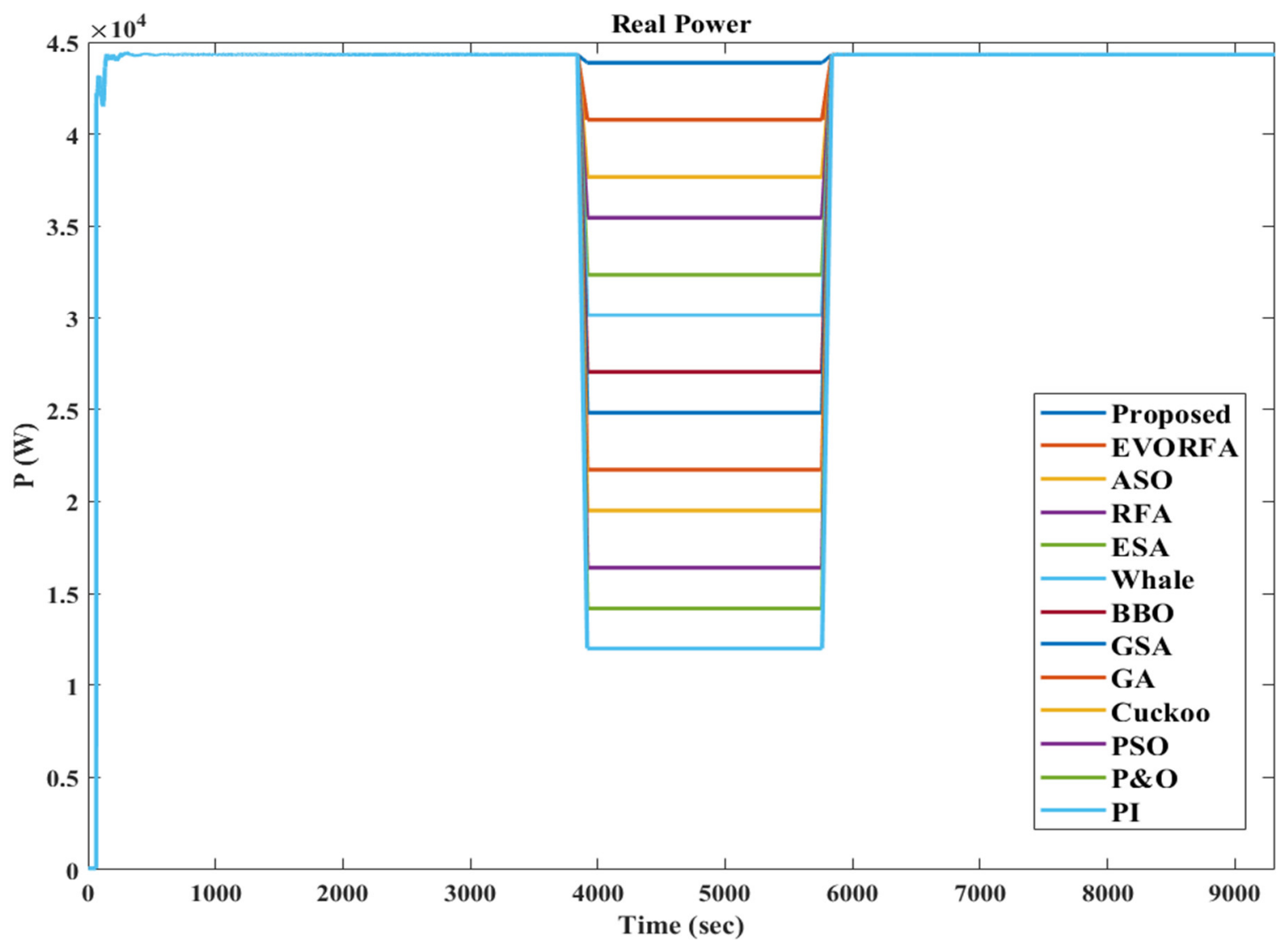

(a)

Figure 21. Cont. 


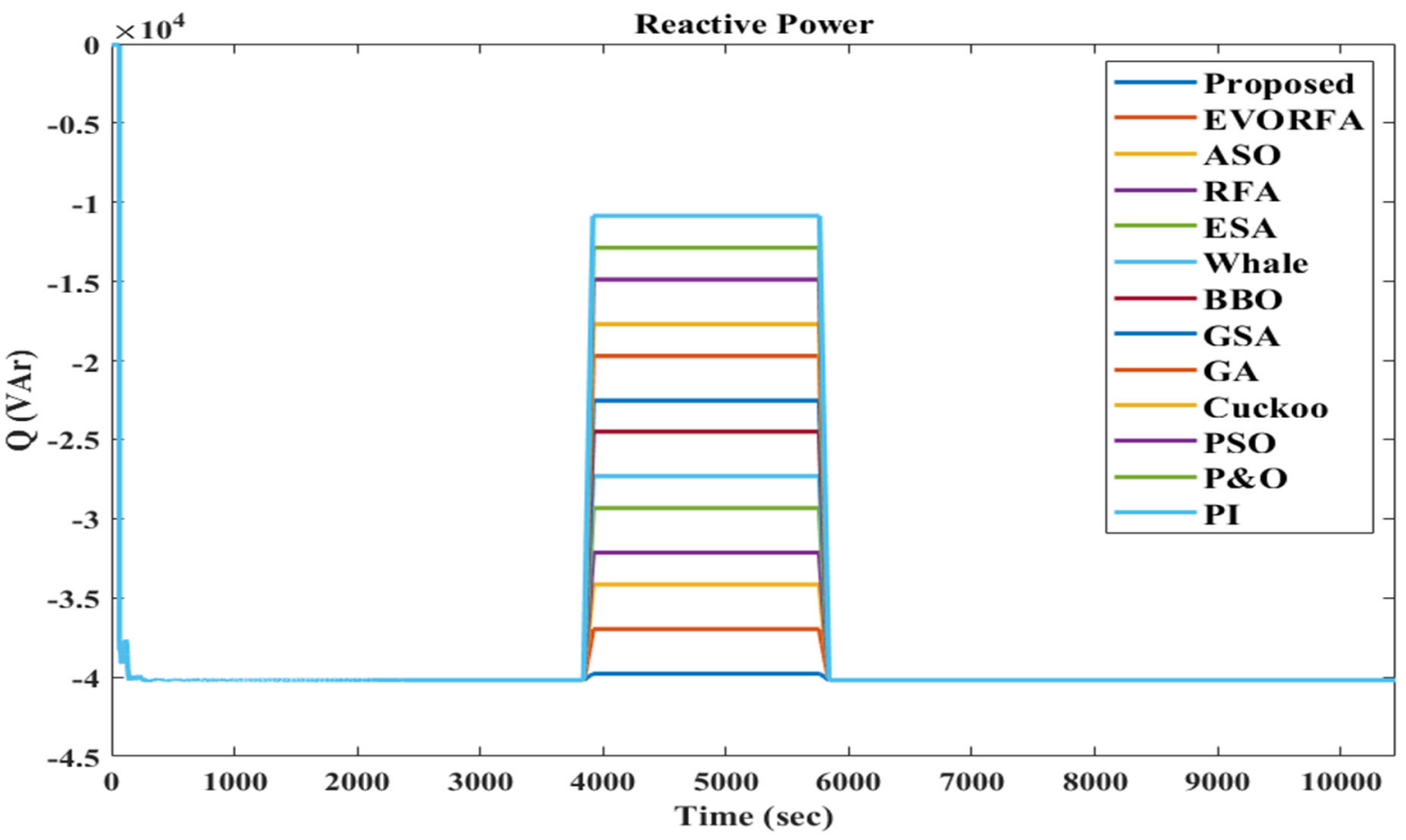

(b)

Figure 21. Comparison analysis of (a) real power and (b) reactive power.
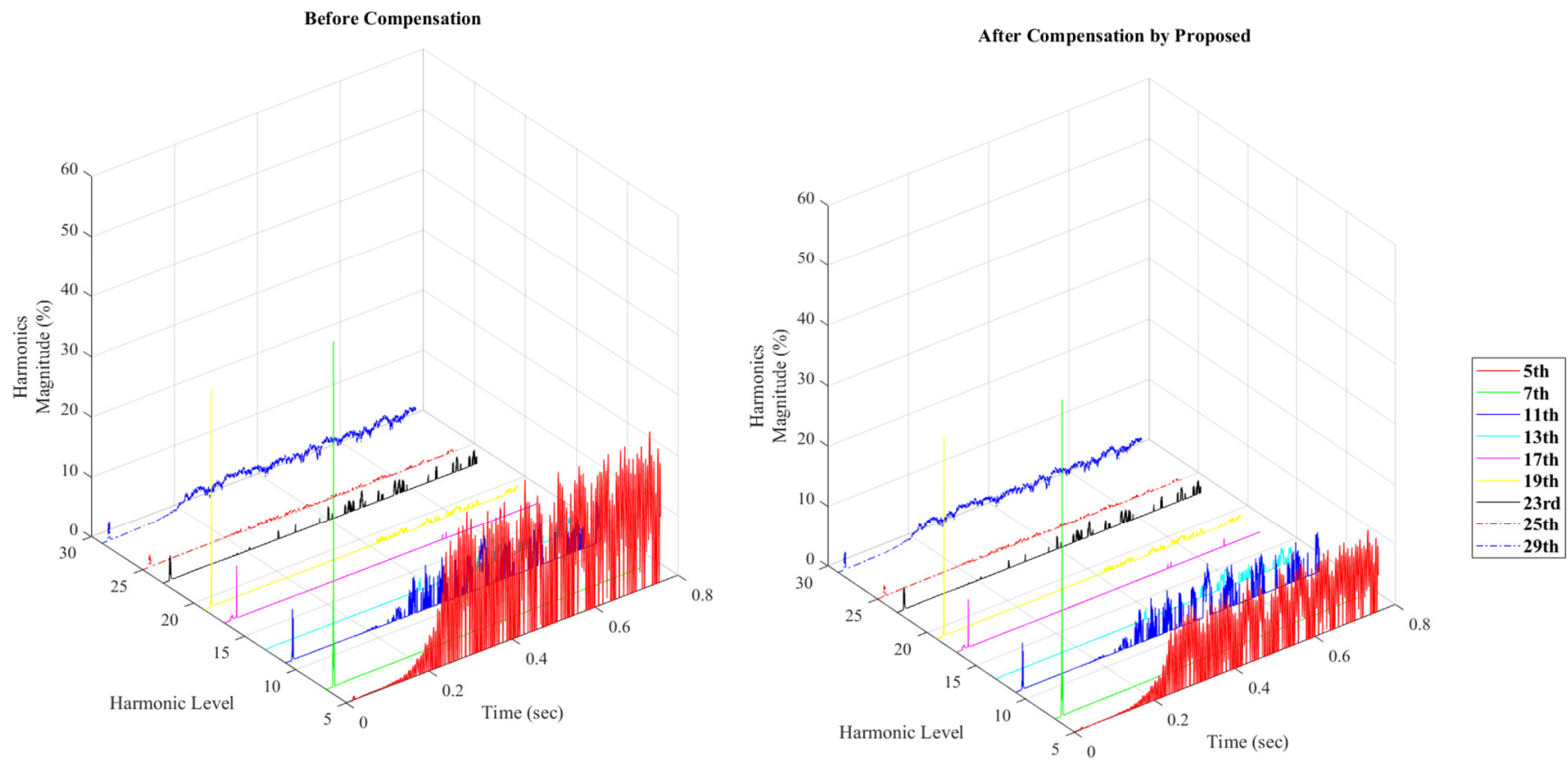

(a)

Figure 22. Cont. 

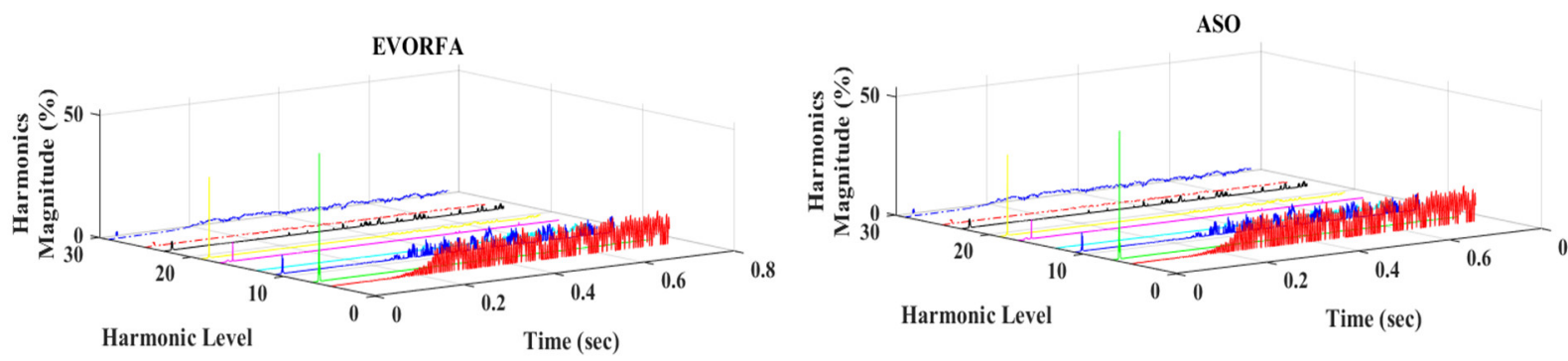

RFA
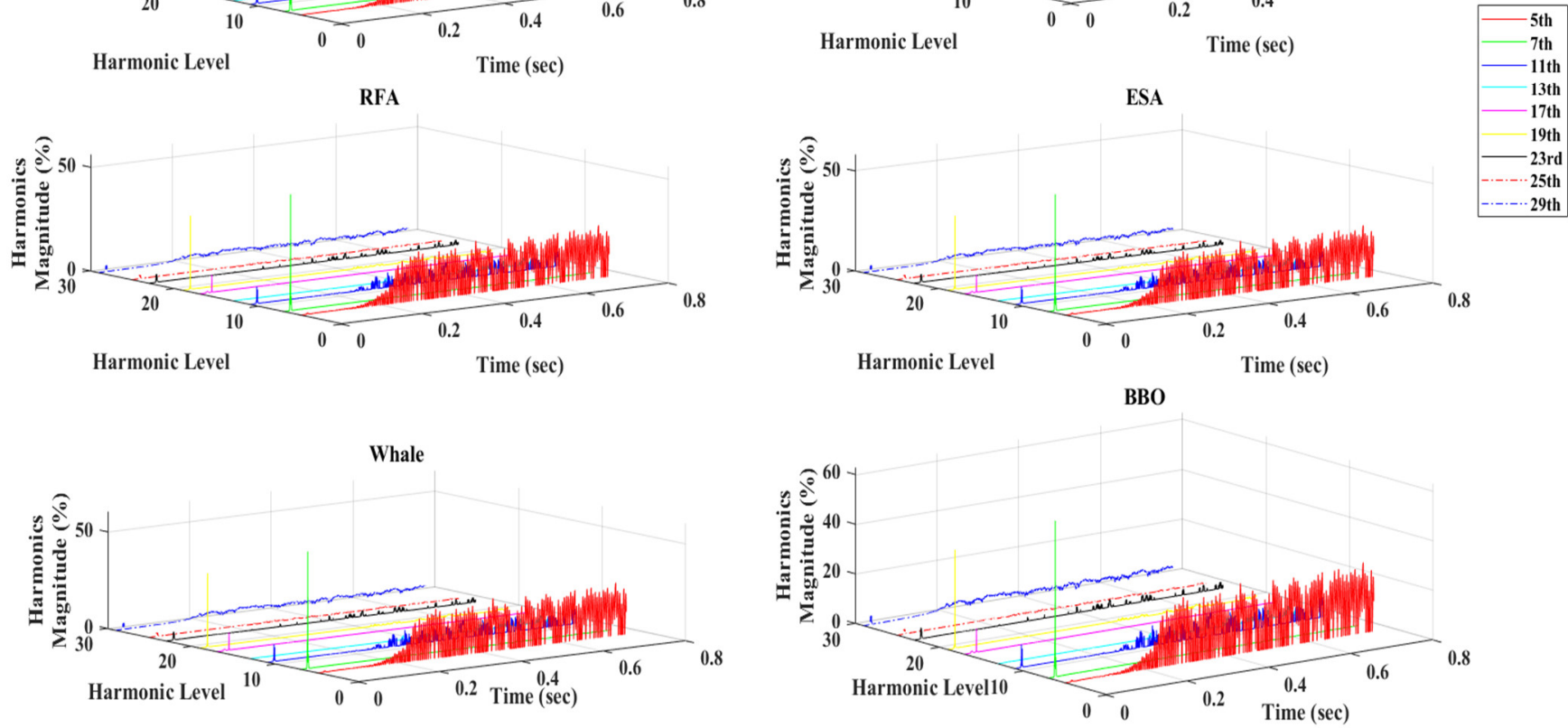

GSA

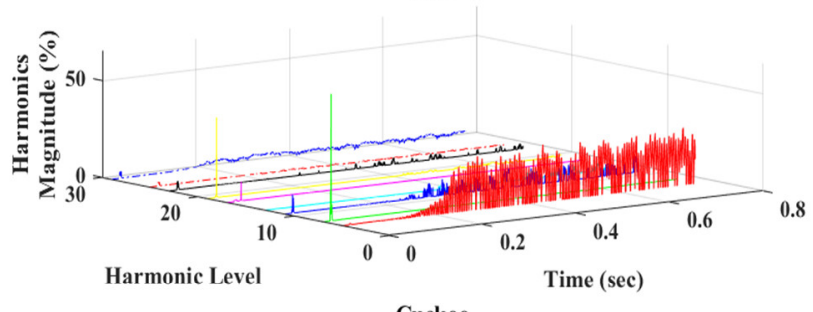

GA
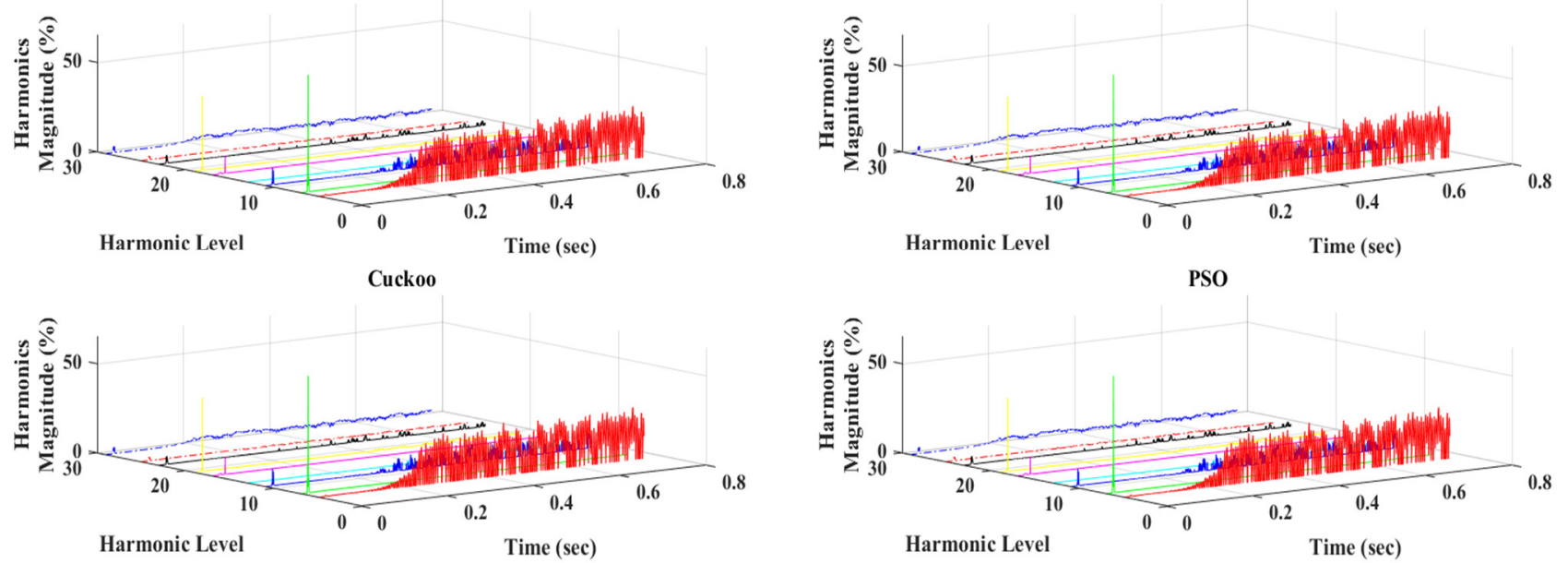

PI

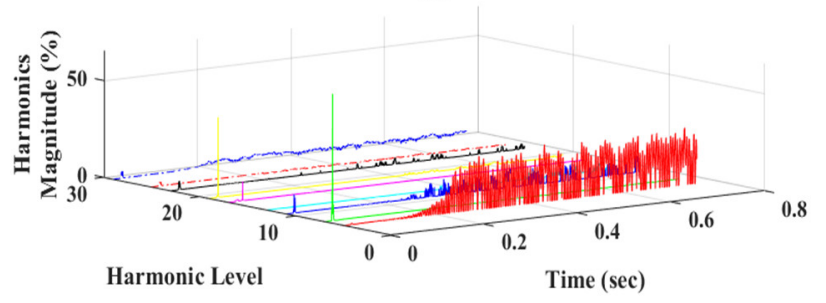

(b)

Figure 22. Comparison analysis of THD: (a) proposed method and (b) existing methods. 


\section{Conclusions}

Power quality improvement in HRES grid-connected systems has become a more advanced research area in DG integrated with HRES systems to eliminate PQ problems. With the use of non-linear loads, instability load, and high-frequency switching characteristics on the load side, $\mathrm{PQ}$ issues in the device are increased. FACT devices are playing an important role in solving the PQ issues in the HRES integrated system. DPFC is proposed to solve the PQ problems and compensate for the load demand. The HRES system is modeled with a DPFC device with a BWO-FOPID controller. DPFC is equipped with two proposed controllers, series active power filters and shunt active power filters. With the utilization of the DPFC system, the voltage and existing PQ problems are mitigated. In MAT$\mathrm{LAB} /$ Simulink framework, the proposed approach was designed and validated. To verify the proposed procedure, three separate cases are evaluated by connecting non-linear loads such as sag, swell, disruption, and harmonics on the grid side. The proposed BWO-based FOPID controller is compared with $\mathrm{P} \& \mathrm{O}, \mathrm{PSO}$, Cuckoo, GA, GSA, BBO, Whale, ESA, RFA, ASO, EVORFA, and PI. The efficiency of the proposed approach has obtained the strongest results in terms of THD.

Author Contributions: Conceptualization, B.S.G.; methodology, B.S.G.; software, B.S.G.; validation, B.S.G.; formal analysis, B.S.G.; investigation, B.S.G.; resources, B.S.G. and M.B.; data curation, B.S.G.; writing-review and editing, B.S.G., M.B., E.E.E. and S.K.; visualization, B.S.G.; supervision, B.S.G.; project administration, B.S.G., C.R.R., E.E.E. and S.K.; funding acquisition, B.S.G., E.E.E. and S.K. All authors have read and agreed to the published version of the manuscript.

Funding: This work was supported by Taif University Researchers Supporting Project number (TURSP-2020/86): Taif University, Taif, Saudi Arabia.

Institutional Review Board Statement: Not applicable.

Informed Consent Statement: Not applicable.

Data Availability Statement: Not applicable.

Conflicts of Interest: The authors declare no conflict of interest.

\section{Abbreviations}

$\begin{array}{ll}\text { ASO } & \text { Atom Search Optimization } \\ \text { BBO } & \text { Biogeography Based Optimization } \\ \text { ESA } & \text { Extended Search Algorithm } \\ \text { EVORFA } & \text { Egyptian Vulture Optimization Random Forest Algorithm } \\ \text { GA } & \text { Genetic Algorithm } \\ \text { GSA } & \text { Genetic Search Algorithm } \\ \text { PSO } & \text { Particle Swarm Optimization } \\ \text { RFA } & \text { Random Forest Algorithm }\end{array}$

\section{LIST OF SYMBOLS}

$\begin{array}{ll}a & \text { Diode ideality factor } \\ B^{P} & \text { Battery power } \\ C R & \text { Cannibalism } \\ D O D & \text { Depth of discharge rate of battery } \\ e^{i} & \text { Source voltage } \\ e(s) & \text { Error signal of HRES system } \\ G(s) & \text { FOPID controller Transfer function } \\ I_{S c} & \text { Current } \\ I^{i s} & \text { Line current } \\ I^{i h} & \text { The output current of shunt active filter } \\ I^{i L} & \text { Load current }\end{array}$




\begin{tabular}{|c|c|}
\hline$I^{l \alpha}, I^{l \beta}$ & Phase neutral currents \\
\hline$I^{L a}, I^{L b}, I^{L c}$ & Three-phase load currents \\
\hline$I^{R a}, I^{R b}, I^{R c}$ & Reference current of shunt active power filter \\
\hline$k$ & Boltzmann's constant \\
\hline$K_{p}$ & Proportional parameters \\
\hline$K_{i}$ & Integral parameters \\
\hline$K_{d}$ & Derivative parameters \\
\hline$N_{p v}(t)$ & Number of cells in the PV array \\
\hline$P_{P V}(t)$ & Power of PV \\
\hline$P_{W T}^{M A X}$ & Maximum power of $\mathrm{WT}$ \\
\hline$P(c)$ & Series filter Active power \\
\hline$P^{L}$ & Demand power \\
\hline$P_{L}(t)$ & Load demand of the system \\
\hline PP & Procreation \\
\hline PM & Rate of Mutation \\
\hline$Q$ & Electron charge \\
\hline$Q(c)$ & Reactive power of the series filter \\
\hline$R_{S E}$ & Series resistance \\
\hline$R_{S H}$ & Shunt resistance \\
\hline$R^{S}$ & Transmission line resistance \\
\hline$s^{-\lambda}, s^{\mu}$ & Fractional order parameters \\
\hline$t$ & Temperature in Kelvin \\
\hline$\mu$ & Battery self-discharge rate \\
\hline $\mathrm{U}(\mathrm{s})$ & Control output \\
\hline$u(s)$ & Controller output \\
\hline$V_{P}$ & The voltage of the cell \\
\hline$V_{p v}(t)$ & Voltage of PV \\
\hline$V^{i h}$ & The output voltage of the series active filter \\
\hline$V(t)$ & Wind speed at time $t$ \\
\hline$V_{r}$ & Nominal wind speed \\
\hline$V_{\text {cutout }}$ & Cut out speed in the WT \\
\hline$V_{\text {cutin }}$ & Cut in the speed of WT \\
\hline$V^{a}, V^{b}, V^{c}$ & Three-phase voltages \\
\hline$V^{d(a c)}$ & Ac component voltage \\
\hline$V^{d(d C)}$ & Dc component voltage \\
\hline$V^{R a}, V^{R b}, V^{R c}$ & Three-phase reference voltages \\
\hline$V^{s a}, V^{s b}, V^{s c}$ & Three-phase supply voltages \\
\hline$X_{1}$ and $X_{2}$ & Parents \\
\hline$Y_{1}$ and $Y_{2}$ & Ancestors \\
\hline$V^{d(a c)}$ & Ac component voltage \\
\hline$V^{d(d C)}$ & Dc component voltage \\
\hline$V^{R a}, V^{R b}, V^{R c}$ & Three-phase reference voltages \\
\hline$V^{s a}, V^{s b}, V^{s c}$ & Three-phase supply voltages \\
\hline$X_{1}$ and $X_{2}$ & Parents \\
\hline $\mathrm{Y}_{1}$ and $\mathrm{Y}_{2}$ & Ancestors \\
\hline
\end{tabular}

\section{References}

1. Bajaj, M.; Singh, A.K. Grid integrated renewable DG systems: A review of power quality challenges and state-of-the-art mitigation techniques. Int. J. Energy Res. 2020, 44, 26-69. [CrossRef]

2. Omar, A.I.; Ali, Z.M.; Al-Gabalawy, M.; Abdel Aleem, S.H.E.; Al-Dhaifallah, M. Multi-Objective Environmental Economic Dispatch of an Electricity System Considering Integrated Natural Gas Units and Variable Renewable Energy Sources. Mathematics 2020, 8, 1100. [CrossRef]

3. Bajaj, M.; Singh, A.K. Hosting capacity enhancement of renewable-based distributed generation in harmonically polluted distribution systems using passive harmonic filtering. Sustain. Energy Technol. Assess. 2021, 44, 101030.

4. Sarker, K.; Chatterjee, D.; Goswami, S.K. A modified PV-wind-PEMFCS-based hybrid UPQC system with combined DVR/STATCOM operation by harmonic compensation. Int. J. Model. Simul. 2020, 41, 1-13. [CrossRef]

5. Mallesham, G.; Kumar, C.S. Power Quality Improvement of Weak Hybrid PEMFC and SCIG Grid Using UPQC. In Advances in Decision Sciences, Image Processing, Security and Computer Vision; Springer: Cham, Switzerland; Hyderabad, India, 2020 ; pp. $406-413$. [CrossRef] 
6. Sedaghati, R.; Shakarami, M.R. A novel control strategy and power management of hybrid PV/FC/SC/battery renewable power system-based grid-connected microgrid. Sustain. Cities Soc. 2019, 44, 830-843. [CrossRef]

7. Bajaj, M.; Singh, A.K.; Alowaidi, M.; Sharma, N.K.; Sharma, S.K.; Mishra, S. Power Quality Assessment of Distorted Distribution Networks Incorporating Renewable Distributed Generation Systems Based on the Analytic Hierarchy Process. IEEE Access 2020, 8, 145713-145737. [CrossRef]

8. Bajaj, M.; Sharma, N.K.; Pushkarna, M.; Malik, H.; Alotaibi, M.A.; Almutairi, A. Optimal Design of Passive Power Filter Using Multi-Objective Pareto-Based Firefly Algorithm and Analysis Under Background and Load-Side's Nonlinearity. IEEE Access 2021, 9, 22724-22744. [CrossRef]

9. Bajaj, M. Design and Simulation of Hybrid DG System Fed Single-Phase Dynamic Voltage Restorer for Smart Grid Application. Smart Sci. 2020, 8, 24-38. [CrossRef]

10. Goud, B.S.; Rao, B.L.; Reddy, C.R. Essentials for Grid Integration of Hybrid Renewable Energy Systems: A Brief Review. Int. J. Renew. Energy Res. 2020, 10, 813-830.

11. Mishra, A.K.; Das, S.R.; Ray, P.K.; Mallick, R.K.; Mohanty, A.; Mishra, D.K. PSO-GWO Optimized Fractional Order PID Based Hybrid Shunt Active Power Filter for Power Quality Improvements. IEEE Access 2020, 8, 74497-74512. [CrossRef]

12. Quynh, N.V.; Ali, Z.M.; Alhaider, M.M.; Rezvani, A.; Suzuki, K. Optimal energy management strategy for a renewable-based microgrid considering sizing of battery energy storage with control policies. Int. J. Energy Res. 2020, 45, 1-15. [CrossRef]

13. Goud, B.S.; Rao, B.L. Power quality improvement in hybrid renewable energy source grid-connected system with grey wolf optimization. Int. J. Renew. Energy Res. 2020, 10, 1264-1276.

14. Nazir, M.S.; Ali, Z.M.; Bilal, M. Environmental impacts and risk factors of renewable energy paradigm-A review. Environ. Sci. Pollut. Res. 2020, 27, 33516-33526. [CrossRef] [PubMed]

15. Aljendy, R.; Nasyrov, R.R.; Abdelaziz, A.Y.; ZakiDiab, A.A. Enhancement of Power Quality with Hybrid Distributed Generation and FACTS Device. IETE J. Res. 2019, 1-12. [CrossRef]

16. Mohammadi, M.; Montazeri, M.; Abasi, S. Bacterial graphical user interface oriented by particle swarm optimization strategy for optimization of multiple type DFACTS for power quality enhancement in distribution system. J. Cent. South Univ. 2017, 24, 569-588. [CrossRef]

17. Chatterjee, A.; Mohanty, K.; Kommukuri, V.S.; Thakre, K. Power quality enhancement of single phase grid tied inverters with model predictive current controller. J. Renew. Sustain. Energy 2017, 9, 015301. [CrossRef]

18. Agarwal, R.K.; Hussain, I.; Singh, B. Application of LMS-based NN structure for power quality enhancement in a distribution network under abnormal conditions. IEEE Trans. Neural Netw. Learn. Syst. 2017, 29, 1598-1607. [CrossRef] [PubMed]

19. Panda, A.K.; Patnaik, N. Management of reactive power sharing \& power quality improvement with SRF-PAC based UPQC under unbalanced source voltage condition. Int. J. Electr. Power Energy Syst. 2017, 84, 182-194.

20. Lakshmi, S.; Ganguly, S. Modelling and allocation of open-UPQC-integrated PV generation system to improve the energy efficiency and power quality of radial distribution networks. IET Renew. Power Gener. 2018, 12, 605-613. [CrossRef]

21. Hossain, E.; Tür, M.R.; Padmanaban, S.; Ay, S.; Khan, I. Analysis and mitigation of power quality issues in distributed generation systems using custom power devices. IEEE Access 2018, 6, 16816-16833. [CrossRef]

22. Choi, W.; Lee, W.; Han, D.; Sarlioglu, B. New configuration of multifunctional grid-connected inverter to improve both currentbased and voltage-based power quality. IEEE Trans. Ind. Appl. 2018, 54, 6374-6382. [CrossRef]

23. Sivakumar, M.; Kannan, P.; Chenthur Pandian, S. Mitigation of PQ issues using an enhanced UPQC-based ANN approach. J. Circuits Syst. Comput. 2019, 28, 1950046. [CrossRef]

24. Sunitha, D.; Arun Bhaskar, M.; Anjana, S.V.; Senthil Kumar, V.; Subhransu, S.D. Power Quality Enhancement with Wind Energy Coupled UPQC with Adaptive Controller. In Proceedings of the 8th International Conference on Renewable Energy Research and Applications (ICRERA), Brasov, Romania, 3-6 November 2019; pp. 898-903.

25. Chaudhary, P.; Singh, G. Fault mitigation through multi converter UPQC with hysteresis controller in grid connected wind system. J. Ambient. Intell. Humaniz. Comput. 2020, 11, 5279-5295. [CrossRef]

26. Durairasan, M.; Balasubramanian, D. An efficient control strategy for optimal power flow management from a renewable energy source to a generalized three-phase microgrid system: A hybrid squirrel search algorithm with whale optimization algorithm approach. Trans. Inst. Meas. Control. 2020, 42, 1960-1976. [CrossRef]

27. Devi, M.S.; Kumar, V.S. Optimized FOPID controller for power quality enhancement between feeders using interline dynamic voltage restorer. Mater. Today Proc. 2021, in press. [CrossRef]

28. Rajendran, M. Comparison of Various Control Strategies for UPQC to Mitigate PQ Issues. J. Inst. Eng. Ser. B 2021, 102, 19-29. [CrossRef]

29. Rawa, M.; Abusorrah, A.; Al-Turki, Y.; Mekhilef, S.; Mostafa, M.H.; Ali, Z.M.; Aleem, S.H.E.A. Optimal Allocation and Economic Analysis of Battery Energy Storage Systems: Self-Consumption Rate and Hosting Capacity Enhancement for Microgrids with High Renewable Penetration. Sustainability 2020, 12, 10144. [CrossRef]

30. Sami, L.; Badreddine, B.; Boudjehem, D. Analytical Design of Multi-loop Fractional IMC-PID-Filter Controllers for MIMO System using Equivalent NIOPDT Models. WSEAS Trans. Syst. Control. 2020, 15, 383-393.

31. Thammarat, C.; Puangdownreong, D. Design of Fractional Order PID Controller for Induction Motor Speed Control System by Cuckoo Search. Int. J. Circuits Syst. Signal Process. 2019, 13, 92-96. 
32. Bajaj, M.; Singh, A.K. An analytic hierarchy process based novel approach for benchmarking the power quality performance of grid integrated renewable energy systems. Electr. Eng. 2020, 102, 1153-1173. [CrossRef]

33. Rekha, R.; Goud, B.S.; Reddy, C.R.; Reddy, B.N. PV-Wind-Integrated Hybrid Grid with P\&O Optimization Technique. In Innovations in Electrical and Electronics Engineering; Springer: Singapore, 2020; pp. 587-600.

34. Reddy, C.R.; Reddy, A.S.; Kumar, C.N.; Ahmed, M.I.; Reddy, D.R.; Goud, B.S.; Aymen, F. Power Quality Improvement in Integrated System using Inductive UPQC. Int. J. Renew. Energy Res. 2021, 11, 566-576.

35. Suresh, V.; Muralidhar, M.; Kiranmayi, R. Modelling and optimization of an off-grid hybrid renewable energy system for electrification in a rural area. Energy Rep. 2020, 6, 594-604. [CrossRef]

36. Madaria, P.K.; Bajaj, M.; Aggarwal, S.; Singh, A.K. A Grid-connected Solar PV Module with Autonomous Power Management. In Proceedings of the 2020 IEEE 9th Power India International Conference (PIICON), Murthal, India, 28 February-1 March 2020; pp. 1-6.

37. Devassy, S.; Singh, B. Modified pq-Theory-Based Control of Solar-PV-Integrated UPQC-S. IEEE Trans. Ind. Appl. 2017, 53, 5031-5040. [CrossRef]

38. Naidu, R.P.K.; Meikandasivam, S. Power quality enhancement in a grid-connected hybrid system with coordinated PQ theory and fractional order PID controller in DPFC. Int. J. Sustain. Energy Grids Netw. 2020, 21, 100317. [CrossRef]

39. Yu, J.; Xu, Y.; Li, Y.; Liu, Q. An Inductive Hybrid UPQC for Power Quality Management in Premium-Power-Supply-Required Applications. IEEE Access 2020, 8, 113342-113354. [CrossRef]

40. Rao, G.S.; Goud, B.S.; Reddy, C.R. Power Quality Improvement using ASO Technique. In Proceedings of the 20219 th International Conference on Smart Grid (icSmartGrid), Setubal, Portugal, 1 July 2021; pp. 238-242. [CrossRef]

41. Goud, B.S.; Rao, B.L. Power quality enhancement in grid-connected PV/wind/battery using UPQC: Atom search optimization. J. Electr. Eng. Technol. 2021, 16, 821-835. [CrossRef]

42. Yuan, Z.; de Haan, S.W.; Ferreira, J.B.; Cvoric, D. A FACTS device: Distributed power-flow controller (DPFC). IEEE Trans. Power Electron. 2010, 25, 2564-2572. [CrossRef]

43. Goud, B.S.; Rao, B.L.; Reddy, B.N.; Rajesh, N.; Anjan, B.; Reddy, C.R. Optimization Techniques in PV-Wind based Distribution Generation-A Brief Review. In Proceedings of the 2020 IEEE 17th India Council International Conference (INDICON), New Delhi, India, 11-13 December 2020; pp. 1-6.

44. Goud, B.S.; Rao, B.L.; Reddy, C.R. An intelligent technique for optimal power quality reinforcement in a grid-connected HRES system: EVORFA technique. Int. J. Numer. Model. Electron. Netw. Devices Fields 2021, 34, e2833. [CrossRef]

45. Dogra, R.; Rajpurohit, B.S.; Tummuru, N.R.; Marinova, I.; Mateev, V. Fault Detection Scheme for Grid-connected PV based Multi-terminal DC Microgrid. In Proceedings of the 2020 21st National Power Systems Conference (NPSC), Gujarat, India, 17-19 December 2020; pp. 1-6.

46. Reddy, B.N.; Bharathi, M.; Pratyusha, M.; Bhargavi, K.S.; Goud, B.S. Design of a Novel Isolated Single Switch AC/DC Integrated Converter for SMPS Applications. Int. J. Emerg. Trends Eng. Res. 2020, 8, 1111-1119. [CrossRef]

47. Mayer, M.J.; Szilágyi, A.; Gróf, G. Environmental and economic multi-objective optimization of a household level hybrid renewable energy system by genetic algorithm. Appl. Energy 2020, 269, 115058. [CrossRef]

48. Lakhdar, C.; Abdelghani, C.; Salem, A. Optimal design and tuning of novel fractional order PID power system stabilizer using a new metaheuristic BAT algorithm. J. Ain Shams Eng. 2017, 8, 113-125.

49. Nahak, N.; Mallick, R.K. Enhancement of small signal stability of power system using UPFC based damping controller with novel optimized fuzzy PID controller. J. Intell. Fuzzy Syst. 2018, 35, 501-512. [CrossRef]

50. Kalyan, C.N.S.; Goud, B.S.; Reddy, C.; Ramadan, H.S.; Bajaj, M.; Ali, Z.M. Water Cycle Algorithm Optimized Type II Fuzzy Controller for Load Frequency Control of a Multi-Area, Multi-Fuel System with Communication Time Delays. Energies 2021, 14, 5387. [CrossRef]

51. Haider, W.; Hassan, S.; Mehdi, A.; Hussain, A.; Adjayeng, G.O.M.; Kim, C.H. Voltage Profile Enhancement and Loss Minimization Using Optimal Placement and Sizing of Distributed Generation in Reconfigured Network. Machines 2020, 9, 3390.

52. Kalyan, C.N.S.; Venkateswarlu, A.N.; Reddy, C.R.; Goud, B.S.; Prasad, A.G.; Sriram, C.; Aymen, F. Frequency regulation of multi area renewable enrgy source system with practical constraints under fractional order fuzzy controller. Int. J. Renew. Energy Res. 2021, 11, 992-1002.

53. Goud, B.S.; Rao, B.L. An intelligent technique for optimal power quality enhancement (OPQE) in a HRES grid connected system: ESA technique. Int. J. Renew. Energy Res. 2020, 10, 317-328.

54. Rana, A.S.; Bajaj, M.; Gairola, S. Optimal Power Flow Solution in Smart Grid Environment Using SVC and TCSC. In Advanced Communication and Control Methods for Future Smartgrids; IntechOpen: London, UK, 2019; pp. 1-22.

55. Hayyolalam, V.; Kazem, A.A.P. Black widow optimization algorithm: A novel meta-heuristic approach for solving engineering optimization problems. Eng. Appl. Artif. Intell. 2020, 87, 103249. [CrossRef]

56. Goud, B.S.; Rakesh, T.; Rajesh, N.; Reddy, C.R.; Kalyan, C.N.S.; Reddy, B.N.; Aymen, F. Grid integration of renewable enrgy sources using GA technique for improving power quality. Int. J. Renew. Energy Res. 2021, 11, 1390-1402.

57. Reddy, C.R.; Goud, B.S.; Aymen, F.; Rao, G.S.; Bortoni, E.C. Power Quality Improvement in HRES Grid Connected System with FOPID Based Atom Search Optimization Technique. Energies 2021, 14, 5812. [CrossRef] 
58. Dashtadar, M.; Bajaj, M.; Hosseinimoghadam, S.M.S.; Sami, I.; Chodhury, S.; Rehman, A.U.; Goud, B.S. Improving voltage profile and reducing power losses based on reconfiguration and optimal placement of UPQC in the network by considering system reliability indices. Int. Trans. Electr. Energy Syst. 2021, e13120. [CrossRef] 